University of Louisville

ThinkIR: The University of Louisville's Institutional Repository

Electronic Theses and Dissertations

$5-2012$

\title{
Assessing teacher attitude toward the inclusion of students with autism.
}

Stephanie Elaine Wilkerson

University of Louisville

Follow this and additional works at: https://ir.library.louisville.edu/etd

\section{Recommended Citation}

Wilkerson, Stephanie Elaine, "Assessing teacher attitude toward the inclusion of students with autism." (2012). Electronic Theses and Dissertations. Paper 1571.

https://doi.org/10.18297/etd/1571

This Doctoral Dissertation is brought to you for free and open access by ThinkIR: The University of Louisville's Institutional Repository. It has been accepted for inclusion in Electronic Theses and Dissertations by an authorized administrator of ThinkIR: The University of Louisville's Institutional Repository. This title appears here courtesy of the author, who has retained all other copyrights. For more information, please contact thinkir@louisville.edu. 


\title{
ASSESSING TEACHER ATTITUDE TOWARD THE INCLUSION OF STUDENTS WITH AUTISM
}

\author{
By \\ Stephanie Elaine Wilkerson \\ B.A., Lindsey Wilson College, 1994 \\ M.A., Western Kentucky University, 2004 \\ Ed.S., Western Kentucky University, 2006
}

\author{
A Dissertation \\ Submitted to the Faculty of the \\ College of Education and Human Development \\ at the University of Louisville \\ And \\ Graduate Studies and Research at Western Kentucky University \\ in Partial Fulfillment of the Requirements \\ for the Degree of
}

Doctor of Philosophy

Department of Educational Leadership

University of Louisville

Louisville, Kentucky

May 2012 


\section{Copyright 2012 by Stephanie Elaine Wilkerson}

All rights reserved 


\title{
ASSESSING TEACHER ATTITUDE TOWARD THE INCLUSION OF STUDENTS WITH AUTISM
}

\author{
By
}

Stephanie Elaine Wilkerson

B.A., Lindsey Wilson College, 1994

M.A., Western Kentucky University, 2004

Ed.S., Western Kentucky University, 2006

A Dissertation Approved on

April 20, 2012

by the following Dissertation Committee:

Dr. Carl Myers

Dissertation Co-Director

Dr. Ric Keaster

Dissertation Co-Director

Dr. Sharon Spall

Dr. Rich Mancil

Dr. Monica Delano 


\section{DEDICATION}

I would like to dedicate this dissertation to

my husband, Rob, and two sons, Jordan and Dillon. Without their unwavering support and repeated encouragement, I could not have accomplished this achievement. 


\section{ACKNOWLEDGMENTS}

I would like to thank Dr. Carl Myers, co-chair of my dissertation committee, for his steadfast support and guidance. Dr. Myers has been truly self-giving with his time and wisdom throughout this project. I would like to thank Dr. Ric Keaster, co-chair of my dissertation committee, for his leadership throughout this endeavor. His efficiency and thoughtful insight have been invaluable. I would also like to extend my appreciation to my other committee members: Dr. Sharon Spall, Dr. Monica Delano and Dr. Rich Mancil. I would like to thank each of them for the constructive feedback each provided. I would like to thank Dr. Reagan Brown for his assistance with data analysis. A special thanks to Dr. John Keedy who provided direction in the beginning when this journey seemed insurmountable. Lastly, I would like to thank my family and friends who have provided unrelenting support and encouragement as I pursued this goal. 


\title{
ABSTRACT \\ ASSESSING TEACHER ATTITUDE TOWARD THE INCLUSION OF STUDENTS WITH AUTISM
}

\author{
Stephanie Elaine Wilkerson
}

April 20, 2012

The purpose of this research study was to examine the relationship between the attitudes of public school teachers and the inclusion of students with autism in the general education classroom highlighting individual teacher characteristics that correlated with agreement or disagreement with inclusion. Participants included regular and special education teachers currently teaching in a South Central Kentucky educational cooperative. Data were collected from the purposive population using a demographic questionnaire and a modified version of the Teacher Attitudes Toward Inclusion Scale (TATIS, Cullen, Gregory, \& Noto, 2010).

Teacher attitude toward inclusion of students with autism as measured by the modified TATIS was overall positive. Most teachers agreed that both regular and special education teachers were responsible for educating students with autism, and over half were willing to make classroom modifications to meet the individual needs of students with autism. A statistically significant correlation was present between teacher perceptions of professional roles and functions and the following characteristics: degree, age, years of teaching experience, having a student with autism in class, severity level of autism, adequate autism training, and formal autism training. A statistically significant 
correlation was noted between teacher beliefs about the efficacy of inclusion and the following teacher characteristics: frequency of contact with a person with autism, adequate autism training, and formal autism training. A statistically significant correlation was highlighted between teacher perceptions of students with autism and the teacher characteristic of adequate autism training. A statistically significant correlation was noted with the TATIS Full Scale score and the following teacher characteristics: severity level of autism, adequate autism training, and formal autism training. A statistically significant difference was noted between regular and special education teachers when assessing teacher perceptions of professional roles and functions and teacher beliefs about the efficacy of inclusion.

This research suggests that teachers are generally positive toward inclusion of students with autism. A number of specific findings were also found as a result of this research. As examples, the TATIS factor structure was supported with the current, larger - sample of teachers. Older teachers with more teaching experience tended to be less accepting of inclusive practices while special education teachers tended to be more accepting of inclusive practices than regular education teachers. Perhaps most importantly, it was found that a lack of adequate and formal training on autism was consistently related to less positive attitudes toward inclusion. Such a finding has clear implications for school districts wanting to increase positive attitudes toward inclusion of students with autism in regular education classrooms. 


\section{TABLE OF CONTENTS}

PAGE

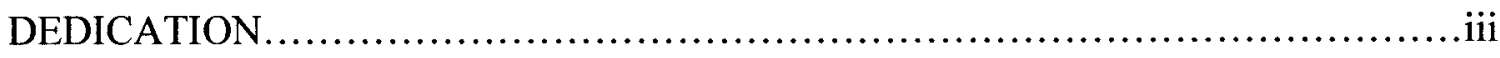

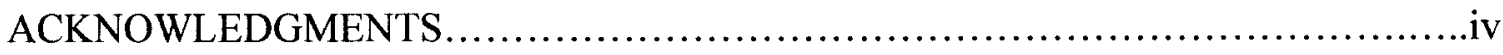

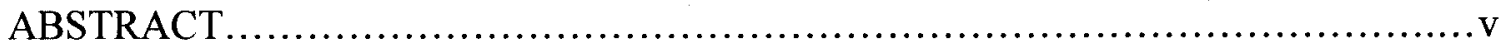

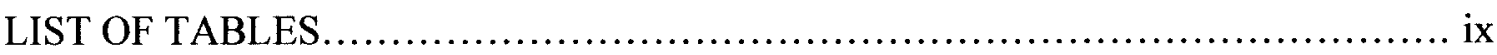

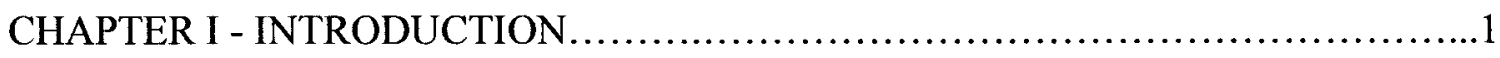

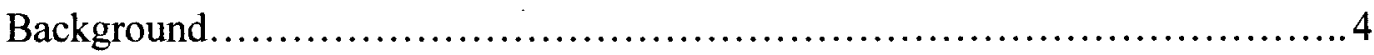

Research Problem.......................................................... 6

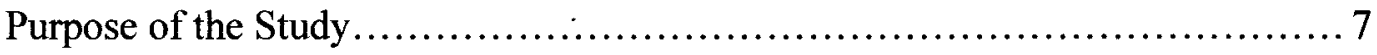

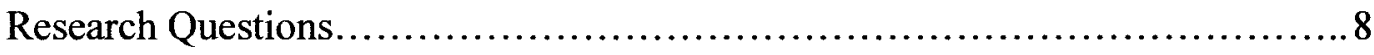

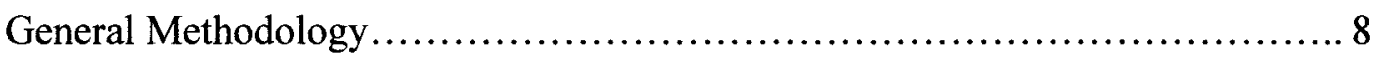

Significance of Study ..................................................... 10

CHAPTER II - REVIEW OF LITERATURE................................... 12

Brief History of Autism.................................................. 12

Brief History of Inclusion................................................ 15

Factors/Characteristics that Influence Attitudes toward Inclusion................20

Teacher Attitude toward Inclusion of Students with Autism.....................73

Summary $\ldots \ldots \ldots \ldots \ldots \ldots \ldots \ldots \ldots \ldots \ldots \ldots \ldots \ldots \ldots \ldots \ldots \ldots \ldots \ldots \ldots \ldots . . .12$ 
CHAPTER III - METHODS AND MATERIALS ............................... 84

Participants........................................................... 84

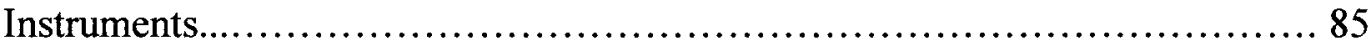

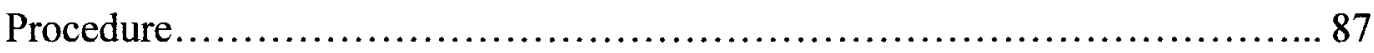

Data Management and Analysis............................................ 88

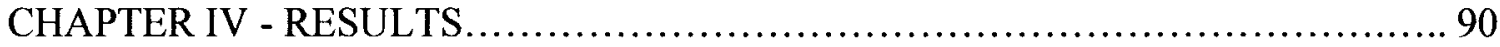

Demographic Data.................................................. 90

Participants' Experiences with Autism................................ 94

Technical Adequacy of the Modified TATIS............................... 97

Research Questions................................................ 99

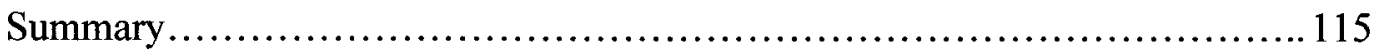

CHAPTER V - CONCLUSIONS AND RECOMMENDATIONS....................117

Findings............................................................... 117

Limitations............................................................... 124

Recommendations.................................................. 125

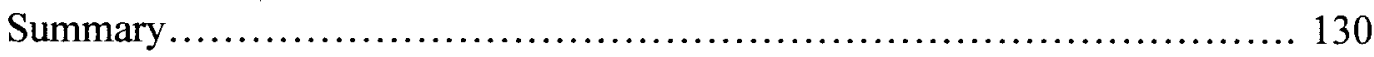

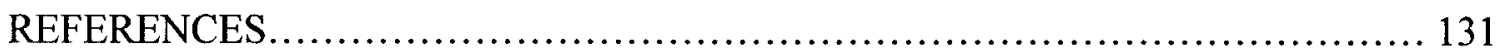

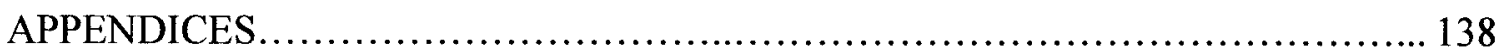

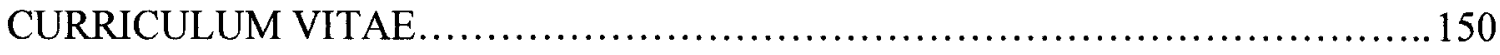




\section{LIST OF TABLES}

TABLE PAGE

1. Participant Demographics................................................ 92

2. Participants' Experiences with Students with Autism and Training on Autism....... 95

3. TATIS Item, Factor and Total Full Scale Means $(n=636) \ldots \ldots \ldots \ldots \ldots \ldots \ldots \ldots 1$

4. Percent of Agreement with each TATIS Item for the Total Sample $(n=636) \ldots \ldots . .104$

5. Mean Scores for Teacher Characteristics on the TATIS......................... 107

6. Mean Scores for Regular and Special Education Teachers' Attitudes............... 114 


\section{CHAPTER I}

\section{INTRODUCTION}

Students with autism are increasingly included within the regular education classroom in the public school setting. This is considered a positive change for students with autism; however, numerous problems still exist as these students transition into the regular education environment. The severity level of the student's autism has been found to influence placement decisions (Eaves \& Ho, 1997). Once placed, teacher attitude toward inclusion of students with disabilities can influence their success within the regular education setting (Elliot, 2008; Simpson, Boer-Ott, \& Smith-Myles, 2003). Personal teacher characteristics such as teaching experience, acquaintance with a person with a disability, income level, level of education, gender, and age have been associated with teacher attitude toward students with disabilities (Alghazo, Dodeen, \& Algaryouti, 2003; Brackenreed \& Barnett, 2006; Jobe \& Rust, 1996).

Previous studies have revealed varied results when assessing teacher attitude toward inclusion of students with autism into the general classroom. Al-Shammari (2006) examined the attitudes of teachers toward students with autism in Kuwait. This study revealed a need for extensive improvement within the Kuwait Autism School for students who have autism; however, teacher attitude was noted to be overall positive toward the idea of inclusion. Similarly, Kasa-Hendrickson and Kluth (2005) revealed positive attitudes of US teachers toward inclusion of students with autism within their classrooms. Teachers were noted to see inclusion as "unconditional" and they did not 
send students away because of behavior or academic difficulties. They embraced the inclusion model and adapted their classrooms to meet the needs of each individual student.

Finke, McNaughton, and Drager (2009) revealed positive and negative themes relating to the inclusion of students with autism who require Augmentative and Alternative Communication (AAC) into regular education classrooms. Teachers reported that there are benefits for inclusion of children who have autism such as social leadership, skill development, or a decrease in challenging behaviors. Teachers indicated that inclusion of students with autism who require $\mathrm{AAC}$ made them a more effective teacher and heightened their awareness of individual student needs. There were also negative themes that emerged from the study. Teachers reported increased stress due to changes in routines, more work in planning and preparation, and increased pressure from parents of students with autism.

Robertson, Chamberlain, and Kasari (2003) surveyed teachers of students with autism and their results indicated that teacher attitude toward inclusion of students with autism was hampered by increased student behavioral problems within the classroom. In this study, increasingly negative behavior by students with autism was a notable characteristic that led to a more negative relationship between the teacher and student, which hindered successful inclusion. A similar study based in France found a correlation between inclusion of students with autism and severity of autism. Negative teacher attitude toward inclusion increased as severity of autism symptoms increased (YianniCoudurier et al., 2008). 
Understanding teacher characteristics or other factors related to attitude toward inclusion of students with autism is important in efforts to reduce negative attitudes toward inclusion in general. Knowing which teachers work best in an inclusive setting can allow school administrators to make educated placement decisions. Parasuram (2006) noted that teachers in India who were older, had a higher level of education, and had a higher income level were likely to have a more positive attitude toward inclusion of students with disabilities into their classrooms. A significant positive interaction was also noted if the teacher was personally acquainted with a person with a disability.

Alghazo et al. (2003) found that educational background influenced pre-service teacher attitude toward inclusion of students with disabilities. Teachers from the college of humanities and education were found to have a more positive attitude toward inclusion of students with disabilities than teachers from the college of science. Gender was also noted to be a characteristic of importance as male teachers were noted to have a more confident attitude toward inclusion of students with disabilities (Brackenreed \& Barnett, 2006; Jobe \& Rust, 1996). Other factors have also been noted when assessing teacher attitude toward inclusion of students with autism. Park and Chitiyo (2011) found that the school level taught (elementary, middle, or high) influenced attitude toward inclusion of students with autism. These researchers revealed that workshop experience that focused on autism positively influenced teacher attitude if the teacher attended at least two workshops.

Limited research has been completed within schools in the US related to assessment of teacher attitude toward the inclusion of students with autism. Of the scant studies conducted around the world, results are conflicting. Some studies clearly identify 
positive attitudes of teachers toward students with autism who are included into the regular education classroom (Al-Shammari, 2006; Kasa-Hendrickson \& Kluth, 2005; Park \& Chitiyo, 2011) while others report mixed or negative attitudes toward such inclusion (Finke et al., 2009; Robertson et al., 2003). Correlations among teacher characteristics or other factors and attitude toward inclusion, both negative and positive, have been highlighted through several studies. If confirmed, this can provide excellent opportunities for public school districts to designate appropriate teachers for inclusive practices within the public school setting (Alghazo et al., 2003; Brackenreed \& Barnett, 2006; Jobe \& Rust, 1996; Parasuram, 2006) or provide supportive resources as they are identified through continued research.

\section{Background}

Autism is a lifelong developmental disability that ranges in severity level from mild to severe (Centers for Disease Control, 2012). Children with autism typically have a "markedly abnormal or impaired development in social interaction and communication and a markedly restricted repertoire of activity and interests" (American Psychiatric Association, 2000, p. 70). Autism can co-exist with other developmental disabilities such as intellectual disability, seizure disorder, attention deficits, fragile $\mathrm{X}$ syndrome, or tuberous sclerosis (Centers for Disease Control, 2012). Autism is typically identified early within a child's development, usually by age three (American Psychiatric Association, 2000). The incidence of autism has exploded within the past decade; yet it remains unclear if the increase is due to an actual increase in children with autism or just differences in awareness and diagnosis (Centers for Disease Control, 2012). The extreme variability of the disability in terms of severity level and coexisting conditions makes it 
difficult for teachers to understand the diverse needs presented by a student with autism who is included within the regular education classroom.

Inclusion is a term used in educational reform that states all students with and without disabilities must be taught together within regular classrooms in their neighborhood school (Crockett \& Kauffman, 1998). Previous terms used in the special education literature were mainstreaming and least restrictive environment. These terms came with the passage of the landmark Education for All Handicapped Children Act of 1975 (Public Law 94-142) that mandated that all children have the right to a "free and appropriate public education in the least restrictive environment." The term mainstreaming evolved with the new law and emphasized placement of students with disabilities in general education classrooms. The Education for All Handicapped Children Act was revised over the years with a noticeable revision in 1990. Congress renamed the act calling it the Individuals with Disabilities Education Act (IDEA). This revision expanded the definition of disabilities to include autism and traumatic brain injury. The term inclusion came with this revision in 1995, which specifically addressed inclusion of students with disabilities in regular classes (Shanker, 1995). Inclusion of students with disabilities within the regular education setting hinges on the term least restrictive environment that is found in IDEA, 2004. Section 612(a)(5) of the IDEA (2004) defines the least restrictive environment as follows:

To the maximum extent appropriate, children with disabilities, including children in public or private institutions or other care facilities, are educated with children who are not disabled, and special classes, separate schooling, or other removal of children with disabilities from the regular educational environment occurs only 
when the nature or severity of the disability of a child is such that education in regular classes with the use of supplementary aids and services cannot be achieved satisfactorily. (http://idea.ed.gov/explore/view/p/,root,statute,I,B,612,a)

To remain in compliance with this federal mandate, schools are obligated to place students with disabilities in their least restrictive environment, which is, in most cases, within the regular education classroom.

The No Child Left Behind (NCLB) act has initiatives that also promote inclusion. NCLB requires public school systems to disaggregate achievement data forcing them to look at students with disabilities as a separate group (Cullen, Gregory, \& Noto, 2010). Public schools are currently held responsible for the progress of students with disabilities in the general curriculum; therefore, it is of utmost importance that these students are exposed to the regular education curriculum to the maximum extent possible. This makes successful inclusion of students with disabilities important for stakeholders within the educational realm. Inclusion must be successful in order for students with disabilities to profit from participation within the regular education environment; however, successful inclusion will depend on teacher acceptance.

\section{Research Problem}

General education teachers are currently faced with an increasing number of students with autism entering their classrooms. According to current estimates, 1 out of every 88 children has autism (Centers for Disease Control, 2012). Inclusion of students with autism into general education classrooms is currently driven by the IDEA and NCLB. In addition, parents of students with autism are strong advocates for inclusion of their children into the regular education classroom. They are adamant that all teachers 
should be trained to work with children who have autism (Jindel-Snape, Douglas, Topping, Kerr, \& Smith, 2005). Regardless of mounting pressure from lawmakers and parents, teachers must be personally willing to accept students with autism into their classrooms for ultimate success (Elliot, 2008; Larrivee \& Cook, 1979). Previous research suggests that many teachers do welcome inclusion of students with autism into their classrooms; however, it is clear that many are not prepared to teach students with autism (Kosmerl, 2011; Monahan \& Marino, 1996; Snyder, 1999). Teachers may perceive students with autism as uneducable within an inclusive setting, which would suggest a lack of knowledge about autism in general. Personal characteristics of teachers (i.e., age, gender, teaching experience, teaching position, or contact with a person who has autism) may be associated with positive or negative attitudes toward inclusion. Understanding teacher attitude toward inclusion and identifying teacher characteristics related to attitude can assist school administrators with the identification of appropriate teachers to work with students who have autism. This will ensure student needs are met within their least restrictive environment in the public school setting as mandated by federal and state laws. Understanding teacher attitude can also provide insight into ways to alter the negative perceptions that many teachers have toward inclusion of students with disabilities in general.

\section{Purpose of the Study}

The purpose of this study is to examine the attitudes of teachers toward the inclusion of students with autism into the regular education classroom and to examine the relationship of personal characteristics and attitude toward such inclusion. Additionally, the factor structure of the modified TATIS used within this study was examined. 


\section{Research Questions}

There were three research questions that guided this study:

1. What are the attitudes of public school teachers toward inclusion of students with autism?

2. Are there specific teacher characteristics related to teacher attitude toward inclusion of students with autism?

3. Are there differences between regular and special education teachers' attitudes toward inclusion of students with autism?

\section{General Methodology}

Permission was obtained from the institutional review boards at both the University of Louisville and Western Kentucky University. The participants for this study were certified regular and special education teachers employed within the 16 districts served by the Wilderness Trail Educational Cooperative (WTEC) in South Central Kentucky for the 2011-2012 school year. This investigator requested the total number of certified teachers teaching within each WTEC district from the Kentucky Department of Education. The resulting total was 2,627 for the 16 school districts and all were provided the opportunity to complete a survey for this study. Each was sent an email that included a description of the present study along with a link that allowed for participation in the study. The study was conducted electronically through Survey Monkey ${ }^{\mathrm{TM}}$ survey software, which is a web based program that allows for easy survey dissemination via email. By clicking on the link, the teacher consented to study participation and was then presented with a demographic questionnaire and an adapted Teacher Attitudes Toward Inclusion Scale (TATIS). 
An incentive to participate was provided to all teachers who completed the survey within the designated time frame. Each teacher who completed the survey had the opportunity to place his or her name in a drawing for an Apple iPad2. Once data collection was completed, a random drawing was conducted to determine the winner for the Apple iPad2. A reminder email was sent to all teachers each week for a total of four weeks by this investigator to encourage survey completion. Collection time lasted for one month, which allowed adequate time for teacher completion within each school district.

The demographic questionnaire was developed by this researcher and elicited basic descriptive characteristics of each teacher including age, gender, degree status, years of teaching experience, national board certification, having a close family member with autism, being personally acquainted with a person who has autism (not a family member), frequency of contact with a person who has autism, having a student with autism in class and the severity level of that student, being adequately trained to teach students with autism, and having formal training in autism. The demographic questionnaire also distinguished regular education teachers and special education teachers. The special education teachers were asked to specify whether they collaborate or teach in a resource setting. This questionnaire was used to address the second and third research questions.

The TATIS, developed by Cullen et al. (2010), was used to address the first research question. Construct validity was confirmed through principal component analysis. This procedure revealed three factors that accounted for over $58 \%$ of the total variance. The three factors were (a) teacher perceptions of students with mild to 
moderate disabilities (POS), (b) beliefs about the efficacy of inclusion (BEI), and (c) perceptions of professional roles and functions (PRF). Once completed, the TATIS was scored using a scoring sheet that provided factor and total scale scores that may be compared to normative standards. T-scores and percentile ranks are provided. Higher scores on the TATIS related to support for inclusion (Cullen et al., 2010).

The TATIS was slightly modified by this investigator for the present study. The term mild to moderate disabilities throughout the TATIS was substituted with the term autism. To determine if this minor substitution affected the norms for the TATIS, this investigator tested the factor structure of the modified TATIS.

Significance of Study

The successful inclusion of students with autism is important to understand, as there are an increasing number of students diagnosed with autism being included within the public school system. As noted earlier, teacher attitude toward inclusion of students with disabilities has been linked to student success within the regular education setting (Elliot, 2008; Simpson, Boer-Ott, \& Smith-Myles, 2003). It is essential to understand teacher attitude toward students with autism in order to provide those students an opportunity to be successful within their least restrictive educational setting. Understanding the relationship between teacher attitude and characteristics or related factors could provide administrators with valuable insight when placing students with autism into regular education classrooms. It may also provide insight into ways to change teacher attitude toward inclusion of students with autism.

This study provides a wealth of information to educational administrators at the state and local levels as they attempt to provide the most appropriate educational 
opportunities to students with autism. It is important to autism research based on the limited understanding of teacher attitude toward inclusion of students with autism. Research within this area is inadequate within the United States yet essential for the successful inclusion of students who have autism. Providing appropriate support and placement to students with autism will provide these students with the best chance for educational success. 


\section{CHAPTER II}

\section{REVIEW OF LITERATURE}

The purpose of this chapter is to provide an overview of the relevant literature pertinent to this study. This research addressed the following areas related to inclusion of students with autism: (a) brief history of autism, (b) brief history of inclusion, (c) factors and/or characteristics that influence attitudes toward inclusion of students with disabilities, and (d) teacher attitudes toward inclusion of students with autism. This review provides a brief history of autism and highlights the history of inclusion to provide insight into the development of inclusive practices within the educational system. Previous research on attitudes of pre-service teachers, teachers, and administrators toward inclusion in general was examined. Research on teacher attitudes toward students with autism was gathered to provide information specific to this disability category. Finally, a summary has been provided to provide an overview of the information from this chapter.

\section{Brief History of Autism}

The term autism was first described by Leo Kanner in 1943 in his landmark paper, Autistic Disturbances of Affective Contact, in which he described the distinct behaviors of 11 children that were markedly different from any other condition he had treated (Kanner, 1943). Kanner was a child psychiatrist at John Hopkins University where he was considered the father of child and adolescent psychiatry. In 1943, he began a study of 11 children that seemed to have some of the common symptoms of childhood schizophrenia yet displayed obsessive and repetitive behaviors, echolalia, and social 
deficits not found with that disorder (Sanders, 2009). Kanner noted that the fundamental core issue with this new disorder was the child's inability to relate to others or objects in a normal way. He described this as "extreme aloneness" (Blacher \& Christensen, 2011). Kanner also noticed that these children did not have the hallucinations or family history of mental illness found with childhood schizophrenia. Kanner termed the new condition "early infantile autism" (Kanner, 1943).

The term "autistic" is derived from the Greek word "autos" meaning "self" which in the context of the disorder of autism is meant to portray the obvious disconnect from the social world around them (Sanders, 2009). Kanner described some of his early child patients as "perfectly oblivious to everything about him" and "acting as if people weren't there" (Kanner, 1943). Four of the eleven children Kanner originally studied were considered deaf or hard of hearing early on (Blacher \& Christensen, 2011). Early descriptions from Kanner noted intense anxiety in these children when presented with change, specific objects or unannounced events as well as frustration with their inability to understand social conventions (Nicpon, Doobay, \& Assouline, 2010).

Although autism was formally documented by Kanner in 1943, the disorder would not be recognized as a distinct disorder until its appearance in the Diagnostic and Statistical Manual - Third Edition (DSM-III) in 1980 as Infantile Autism (American Psychiatric Association, 1980). However, as early as 1952 with the first publication of the DSM, there were elements of autism present under criteria for schizophrenic disorders (Sanders, 2009), which meant most children presenting with such symptoms were labeled with a type of schizophrenia. The current Diagnostic and Statistical Manual - Fourth Edition - Text Revision (DSM-IV-TR) provides the following criteria for a 
current clinical diagnosis of autistic disorder: qualitative impairment in social interaction, communication and restricted repetitive and stereotyped patterns of behavior, interests, and activities with onset prior to age three (American Psychiatric Association, 2000).

Similarly, the disorder was not recognized by the U.S. Department of Education as a disability category until 1991 (Ruble \& Dalrymple, 2003). Prior to the development of this category, students with autism were served under other disability categories that did not meet their diverse needs. The current eligibility determination for autism requires that the student meet the following criteria:

(a) have a developmental disability, generally evident before age three, significantly affecting verbal and nonverbal communication; (b) have a developmental disability affecting social interaction; (c) the student's deficits are not primarily the result of an emotional-behavior disability; (d) evaluation information confirms there is an adverse effect on educational performance; (e) evaluation information confirms that lack of instruction in reading and/or math was not a determinant factor in the eligibility decision; and (f) evaluation confirms that limited English proficiency was not a determinant factor in the eligibility decision (Kentucky Administrative Regulations: 707 KAR 1:002, 2008, p.3).

Autism ranges from mild to severe and can impair multiple areas of development including cognitive, sensory, social, communication, and motor areas (Ruble \& Dalrymple, 2002). Kanner described strengths in some of his original 11 child patients indicating that some displayed good cognitive potential and those who spoke an excellent 
vocabulary (Sanders, 2009). To further complicate the varied characteristics of autism, one must consider that many diagnosed with autism also have co-existing conditions such as mental retardation, tuberous sclerosis, seizure disorder or other syndromes (Ruble \& Dalrymple, 2002). This variability in the disorder along with co-existing disorders makes it extremely difficult for teachers who are expected to provide instruction to students who have autism. In order to accomplish such a task, they must be educated and provided with a wealth of resources and support in order to offer adequate services to children with autism within their least restrictive educational setting.

\section{Brief History of Inclusion}

Inclusion is a term that has evolved over several decades within the educational setting. As early as the 1900 s, courts were upholding court cases that excluded students with disabilities from public education. In Wisconsin, in the court case Beattie v. Board of Education (1919), the court held that a student with a condition that caused him to drool could be expelled from the public school because his behavior "nauseated" the teacher and other students (Alexander \& Alexander, 2009). In Illinois, in the court case Welfare v. Haas (1958), the court held that the state was not required to provide a free public education for the "feeble minded" or the "mentally deficient," since they were unable to reap the benefits of such an education (Yell, Rogers, \& Rogers, 1998).

The Civil Rights Movement of the 1950s led to litigation that would provide minorities equality of opportunity within the United States, particularly African Americans. The landmark case of Brown v. Board of Education (1954) was a key victory for this liberating movement and continues to be the major underpinning for all civil rights action. This case provided an opening for advocates for special education students. 
With strong parental advocacy leading the way for students with disabilities, the decision in Brown v. Board of Education eventually led to changes in school policies related to the rights of students with disabilities (Yell et al., 1998).

During this time, the federal government began to develop and implement programs and services for children with disabilities. Examples included federal legislation such as the Captioned Films Acts of 1958 (Public Law 85-905) which held provisions that included training for teachers of students who had mental retardation (Public Law 85-926) and the Teachers of the Deaf Act of 1961 (Public Law 87-276) that provided instructional training for children who were deaf or hard of hearing. Public Law 88-164 expanded these specific training programs to include training for all types of disabilities. In 1965, the Elementary and Secondary Education Act (Public Law 89-10) was implemented due to strong parental advocacy for the education of students with disabilities. This law provided states with financial assistance to help educate children who had disabilities.

Two court cases would set the stage for the concept of equal opportunity for children with disabilities within the eyes of the court. The first was a case in Pennsylvania, Pennsylvania Association for Retarded Citizens (PARC) v. Commonwealth of Pennsylvania (1972), which found that all children between the ages of 6 and 21 years must be provided with a free public education in a program similar to that of their nondisabled peers (Alexander \& Alexander, 2009). Similarly, a second case was filed in the District of Columbia, Mills v. Board of Education (1972), which was brought against the local board of education by parents and guardians of seven children with varying disabilities. The court ruled that the children had the right to a publically supported 
education. The court also outlined due process procedural safeguards within this case that were later upheld in the Education for All Handicapped Children Act (EAHCA) of 1975 (Alexander \& Alexander, 2009). These two landmark cases opened the door for students with disabilities across the country; yet, many students were still denied the right to public education with their non-disabled peers. The federal government finally stepped in and hearings that eventually led to laws that would protect these students based on their rights under the Fourteenth Amendment began.

In 1970, the Education for the Handicapped Act (EHA) was developed which set the basic framework for future legislation and included grants for children with disabilities (Yell et al., 1998). The EAHCA of 1975 (Public Law 94-142) was mandated by President Gerald Ford and stated that all children have the right to a "free and appropriate public education in the least restrictive environment." Senator Harrison Williams, principle author of the EAHCA of 1975 noted:

We must recognize our responsibility to provide education for all children with disabilities that meets their unique needs. The denial of the right to education and to equal opportunity within this nation for handicapped children--whether it be outright exclusion from school, the failure to provide an education which meets the needs of a single handicapped child, or the refusal to recognize the handicapped child's right to grow--is a travesty of justice and a denial of equal protection under the law. (Williams, Congressional Record, 1974, p. 15272)

EAHCA of 1975 took effect on August 23, 1977, and all 50 states participated under the provisions set forth by the act that provided federal funding to teach students with 
disabilities. There were various amendments to the act that clarified and extended its requirements under the law (Yell et al., 1998). With the passage of EAHCA, the term mainstreaming was used to describe the placement of students with disabilities in general education classrooms receiving formal education with their non-disabled peers. A student spending at least half the school day in the general education setting was considered to be in the mainstream (Kavale \& Forness, 2000).

The amendments to EACHA of 1975 that came in 1990 included the renaming of the act. The act would be termed the Individuals with Disabilities Education Act (IDEA) of 1990 and included major changes to the provisions of the act. Most notably, the terms handicapped student were changed to emphasize person first; thus, child/student with a disability and students with autism and traumatic brain injury were identified under separate and distinct categories. Mainstreaming was replaced by the term inclusion, which is not found within IDEA yet hinges on the term least restrictive environment (LRE). LRE provides that students with disabilities are educated with children who are not disabled and should only be removed from this educational environment if the nature or severity of the disability is such that their education cannot be achieved with supplementary aides and services within that setting. This provides for inclusion within the general education classroom for all students with disabilities to the maximum extent possible. Further amendments to IDEA have focused on the inclusion of students who have disabilities and their individual needs with education. The 1997 revisions signed by President Clinton noted mandates for statements of measurable annual goals and benchmarks to determine student progress and a reminder that students with disabilities shall be disciplined in the same manner as their non-disabled peers (IDEA, 1997). 
The No Child Left Behind (NCLB) act adds an accountability factor to the education of students with disabilities. The act requires that public schools receiving federal funds to disaggregate state achievement data which forces schools to identify students with disabilities as a separate group (Cullen et al., 2010). This act provides that states describe how they will close the achievement gap and ensure all students (including those with disabilities) achieve academic proficiency (McLaughlin, 2010). To achieve such goals, students with disabilities must receive instruction within all content areas, which are taught within the regular education setting. NCLB forced stakeholders to include students with disabilities within the regular education classroom in order for them to have exposure to curriculum content assessed by their state assessment.

Determining whether a school should promote full or partial inclusion of students with disabilities puts schools in a state of flux; yet, the trend is certainly leaning toward greater inclusion of students with disabilities. Federal law demands inclusion for the education of students with disabilities, but difficulties have been noted as this provision has come to be interpreted as solely the general education classroom for all students regardless of disability and severity of that disability (Kavale \& Forness, 2000). Regardless, students with disabilities are being placed within the general classroom and teachers are faced with the reality that they must educate these students within that classroom. Teacher acceptance of inclusive practices and their attitude toward such practices will determine their success and ultimately the success of the student who has a disability. 
Factors and/or Characteristics that Influence Attitudes toward Inclusion Pre-service Teachers

Hastings and Oakford (2003) examined the attitudes of student teachers based on the special needs category of the student and the student teacher training. The first research question assessed the attitude of the student teacher toward inclusion of students who have intellectual and emotional behavioral disabilities. The second research question addressed the attitude of the student teacher based on the age of the student with the disability. Participants were selected from a university where they were being trained to work either with younger children (age 4-11) or older children (11-19). Of the 150 total surveys distributed, 93 were returned for a return rate of $62 \%$. Student teachers were chosen to control for amount of teaching experience and previous experience of special needs training.

This correlation study used an informative questionnaire to obtain demographic data and one attitude questionnaire. The Impact of Inclusion Questionnaire (IIQ) was used to measure teacher attitude toward people with varying disabilities. The IIQ has a 7point Likert scale that rates responses ranging from very strongly agree to very strongly disagree. The IIQ provided a total scale score and four domain scores. The four domains with Cronbach's alpha are as follows: Child with special needs $(\alpha=.74)$; other children $(\alpha=.65)$; teacher $(\alpha=.73)$; and school or classroom environment $(\alpha=.92)$. Two versions of the survey were randomly distributed to teachers. One version had teachers respond based on children with intellectual disabilities and the second version had teachers respond considering students with emotional and/or behavioral disabilities. 
Data analysis included Kolmogorov-Smirnov tests to confirm normal distribution that indicated that the data were normally distributed. Mean scores for each participant were subdivided by age group (younger versus older children) and the disability they were to consider (intellectual versus emotional/behavioral). Demographic data and IIQ scores were explored using $t$-tests and Spearman's rank correlations. Results were not significant; therefore, the demographic data were not included in the analysis of variance. The mean scores for each participant were explored using a 2 X 2 between-subjects analyses of variance.

Results revealed that teachers' attitudes were affected by the nature of the disability (intellectual versus emotional/behavioral). Students with emotional and/or behavioral disabilities were rated as having a more negative impact on the teacher, other children, and the school and classroom environments. Teacher training for specific student age (younger versus older) did not impact teacher attitude.

This study highlighted the fact that teacher attitude is not the only factor relating to the success of inclusion. The type of student disability can influence teacher attitude and thus should be addressed through supports and resources for teachers. This study also demonstrated the need for additional research to further define teacher needs when working with students with disabilities. The IIQ may provide valuable input regarding teacher attitude and could be used to monitor change as a result of teacher training.

In a similar study, Reber, Marshak, Glor-Scheib, and Noll (1995) examined the attitudes of students in a teacher education program toward students with disabilities. The purpose of the study had three parts: (a) analyze factors that might influence the student's attitude toward inclusion such as perceived fairness and feasibility of inclusion, 
(b) examine whether students responded to requests for inclusion differently depending on the disability of the student, and (c) evaluate the effects of pre-service training on attitudes toward inclusion. Participants were students enrolled in a teacher education program in rural Western Pennsylvania. Study participation was based on enrollment in the teacher education program. All enrolled students were divided into three groups. Group A consisted of 59 students who were sophomores, juniors, and seniors. Group B included 100 students who were sophomores, juniors, seniors or graduate students. Group C included 23 senior students.

In this quasi-experimental study, 10 vignettes were developed where each described behavior characteristics of a student with a disability without naming the disability. Students rated four questions after each vignette on a 5-point Likert scale to assess their reaction to the inclusion request. The ratings were (a) fair versus unfair; (b) easy to accomplish versus difficult to accomplish; (c) the extent to which they would welcome the inclusion versus refer the child for alternate placement; and (d) the extent to which they were confident versus anxious about the request. Students completed the surveys during their programs usually during or after class. To ensure validity, the vignettes were reviewed by four professors in special education and rehabilitation.

Data analysis included computation of mean scores for the subject groups for each attitude component, disability condition, and attitude component for disability condition. An analysis of variance using Wilks Lambda revealed three main effects which were as follows: (a) type of pre-service training experience, (b) attitude components, and (c) disability conditions. 
Findings revealed that the type of academic preparation can impact the student attitude during teacher preparation programs. Guided practicum experience increased positive attitudes for students. These students were consistently positive toward inclusion for all requests relating to all disabilities. This study also found that student attitude toward inclusion was based on the nature of the child's disability. Students were most positive about inclusion of students with orthopedic disabilities who require a wheelchair versus students with seizure or behavior disorders. Finally, researchers noted students were generally welcoming toward inclusion of students and regarded inclusion as fair. These findings indicated that appropriate training experiences influence attitudes toward inclusion of students with disabilities. Positive experiences during a student's practicum should be emphasized. This study highlights the need for a focus on inclusion of students with disabilities when training teachers. It also reiterates the notion that student disability type influences attitude as found with Hastings \& Oakford (2003).

Shade and Stewart (2001) examined the effect of an introductory course in special education on the attitudes of general and special education pre-service teachers toward inclusion of students who have disabilities. The study evaluated attitudes before and after the completion of the special education course to assess the effectiveness of the course. Participants included general education majors $(N=122)$ and special education majors $(N$ $=72$ ) enrolled in a required special education course at a major teacher preparation institution. The same instructor taught both courses using the same textbook and related course materials. Participation was based on student enrollment in the course.

In this pre-post design, data collection included a 48 -item inclusion inventory that assessed overall attitude toward inclusion of students with disabilities. This 5-point 
Likert scale instrument was implemented as a pre- and post-test measure to assess any attitudinal change as a result of the special education course. The instrument provided eight subscales: Class Placements (5 survey items); Behavior ( 7 items); Self-Concept ( 7 items); Other Students (9 items); Time and Work (6 items); Teacher (9 items); Motivation ( 3 items); and parents ( 2 items). Teachers rated statements based on these eight subscales rating from 1 (strongly disagree) to 5 (strongly agree). No reliability or validity scores were provided for scale. The independent variable in this study was teacher attitude toward students with autism included in the regular education classroom. The dependent variable was the special education course. Data analysis included using $t$ tests with alpha $<.05$ to determine attitude change after course completion.

Findings revealed an overall positive change in attitude among the general and special education majors. Analysis noted significance among five of the eight subscales for the general education majors (Behavior, Self-Concept, Other Students, Teacher, and Parents) and significance among five of the eight subscales for the special education majors (Class Placement, Behavior, Self-Concept, Motivation, and Parents).

These findings emphasize a connection between teacher attitude toward inclusion and coursework in special education. The study highlights the benefits of regular and special education teacher training in the area of special education which is very useful to teacher preparation programs and school administrators preparing teacher professional development sessions.

Richards and Clough (2004) examined the effects of a postgraduate program on student teachers' attitudes toward inclusion. Participants included 120 students in a oneyear, full-time Post Graduate Certificate of Education (PGCE) cohort at a United 
Kingdom university. Of the 210 student teachers, 90 (75\%) completed the first questionnaire that was distributed in an introductory session the first week of study. The second questionnaire had a $58 \%$ return rate which was given a year later at the end of the program. The decrease in return rate was due to lack of access to all students at the end of the program.

In this pre-post design, data collection included two questionnaires. The first questionnaire, given at the beginning, covered advantages/disadvantages of special and inclusive education programs. It measured the student teachers' understanding of inclusion and their understanding of the identification process for children with disabilities. The second questionnaire, administered after the year-long experience, examined the student teachers' experience of inclusion within the schools and asked if original views of inclusion had changed. No reliability or validity scores were provided for scale. The independent variable in this study was teacher attitude toward inclusion. The dependent variable was the Post Graduate Certificate in Education (PGCE) program. Data analysis included using ratings from the pre- and post-assessment to formulate percentiles to note change.

The first questionnaire noted an overall positive attitude toward inclusion with most students (86\%) indicating that there should be equality for all students. Despite this overall support of inclusion, over half of the student teachers reported concerns about inclusion citing that inclusion would be more work for teachers as they try to meet the various needs of students with disabilities. They also noted concerns about the potential hindrance for general education students' learning when students with disabilities are included in the general classroom. Results from the second questionnaire indicated that 
the majority (76\%) reported that inclusion had been successful within their school. Over half (59\%) of the student teachers' attitude toward inclusion did not change over the year. Forty-one percent of student teachers, however, changed their opinions about inclusion for the positive. Those opinions were found in student teachers that were in schools with appropriate resources available for successful inclusion. Interestingly, only two student teachers reported changing their views on inclusion from supporting it to opposing it. When the student teachers were asked what had most prepared them for inclusive teaching, $95 \%$ reported teaching experience while approximately half reported university training as a positive influence on their inclusive teaching practices.

This study emphasizes the importance of educating teachers about students with disabilities during university training; yet, it highlights the fact that initial student teaching experience may also be a factor that influences teacher attitude. This study can provide insight into teacher attitude as it relates to the student teacher experience. Universities can use this information to promote positive experiences for teachers as they prepare to become educators.

Shippen, Crites, Houchins, Ramsey, and Simon (2005) assessed pre-service teacher perceptions of inclusion before and after an introductory course in special education. The purpose of the study was to compare the pre-service teacher perceptions to inclusion on two scales: hostility/receptivity and anxiety/calmness. Participants were pre-service graduate and undergraduate students from three universities (two located in the southeastern U.S. and one in the mid-Atlantic region of the U.S.). Participants were enrolled in survey of exceptionality courses with the majority female (75\%), future 
general educators (46\%). Surveys were distributed at the first and last class sessions. Survey response rate was not provided.

This quasi-experimental study used a survey adapted from the one used by Soodak et al., (1998) which provided ratings on the dimensions of hostility/receptivity and anxiety/calmness. Hypothetical scenarios were given to the pre-service teachers in which they had to indicate whether they accepted or opposed inclusion of the described student. The student disabilities described in this survey included hearing impairment, learning disability, mental retardation, behavior disorder, or a physical handicap requiring a wheelchair. Two separate scales were found with the Response to Inclusion Survey: hostility/ receptivity and anxiety/calmness. Cronbach's alpha noted adequate reliability with .92 and .87. The scenario was followed with a 17-item, 5-point Likert scale ranging from negative to positive feelings about the scenario.

Data analysis included test-retest reliability, confirmatory factor analysis and a repeated measures multivariate analysis of variance (MANOVA) to determine reliability of the adapted scales (hostility/ receptivity and anxiety/calmness) as well as interactions. Analyses were performed using each scale as a dependent variable. Independent variables included the teacher type (general educator vs. special educator), gender, and class rank (graduate vs. undergraduate). The test-retest reliability analysis confirmed the acceptable Cronbach alphas found with Soodak et al. (1998). The hostility/receptivity subscale yielded a .93 and the anxiety/calmness a .91 with a total reliability coefficient for the entire instrument at .96 . The content validity analysis was conducted by three experts in the field of special education and concluded that all items were relevant. The 
confirmatory analysis yielded a two-factor structure that accounted for $45 \%$ of the total variance. Principal component extraction with varimax rotation confirmed this structure.

Results revealed that teachers became slightly more receptive to inclusion of students with disabilities after taking the introductory special education course. When looking at the first factor hostility/receptivity, pre-service special education teachers were more receptive than general education teachers $(+.31$ for special educators versus +.26 for general). The second factor, anxiety/calmness described the tension teachers felt when they are told they will have a student with a disability in their classroom. Preservice general education teachers were found to have more increase with this factor $(+.54)$ than special educators $(+.33)$. Gender and class rank of pre-service teachers showed no significant differences.

This study highlights the importance of pre-service teachers obtaining quality instruction at the undergraduate and graduate levels. This information is essential for educational institutions that bear the task of educating our future teachers. It is evident that all teachers do benefit from courses in special education.

Brackenreed and Barnett (2006) examined pre-service teacher perceptions regarding behavior management in inclusive classrooms. The study also examined the relationship between teacher attitude/beliefs and demographic information. The design of the study was descriptive. The assessed demographic variables were age and gender. Participants were selected from a small university in northern Ontario, Canada who were enrolled in a Bachelor of Education program. Of the 620 total questionnaires distributed, 428 were returned for a return rate of $69 \%$. 
This descriptive study used a survey that measured attitudes, knowledge, perceptions, values, and behavior. The survey was based on a 4-point Likert scale ranging from 1 (not applicable) to 4 (confident). An acceptable Cronbach alpha (.91) was calculated for the survey. Descriptive statistics were used to analyze demographic pre-teacher variables. Survey data were analyzed using frequencies, means, and standard deviations. A one-way ANOVA and Bonferonni post hoc analyses were used.

Results revealed pre-service teachers were somewhat confident in their behavior management abilities. On the other hand, they reported less confidence in meeting their own personal needs (coping with the stress of classroom management). Pre-service teachers reported a sense of proprietorship over their classrooms. They indicated that they would not likely ask for help nor did they want to appear in need of help. When demographic variables were assessed, females were found to be more willing to implement accommodations or modifications for students with special needs although males expressed more confidence. Females, on the other hand, were found to be more confident when dealing with disrupted teaching and making time for others. Females were also more likely to engage in coping strategies to initiate direct support. The age group of 41-45 year-old pre-service teachers was noted to report higher instances of student withdrawal, symptoms of depression, over affection toward strangers, aggression toward adults and self, unpredictability, and avoidance than any other group. The youngest age group, 20-25 year-olds, were the least likely to request assistance from the principal.

This study highlights a need for further research on this topic. Previous research has hinted that understanding pre-service teacher attitude and factors that influence their 
attitudes is important for administrators and policy makers in the field of education as they oversee teacher placement. Strategic teacher placement may be essential for success within inclusive classrooms. This study provides interesting data regarding pre-service teacher attitudes and confidence levels toward behavior management in inclusive classrooms. Understanding pre-service teacher needs can be extremely important in determining how to meet those needs before teachers begin their teaching careers.

This section has provided an overview of studies that focused on factors and/or characteristics related to pre-service teacher's attitude toward students with disabilities. These studies primarily focused on the effectiveness of teacher training programs in preparing the student teacher to work with students with disabilities while assessing the pre-service teacher attitude toward inclusion of such students. One study examined characteristic variables such as gender and age as related to pre-service teacher attitude toward inclusion of students with disabilities. The next section will focus on factors and/or characteristics related to teacher attitudes toward students with disabilities.

Park and Chitiyo (2010) examined pre-service teachers' attitudes toward children with autism. The purpose of the study was to assess the attitudes of pre-service teachers toward children with autism to provide information to help with the development or improvement of professional development within schools and teacher training programs within the United States. Participants comprised 131 students enrolled in the college of education teacher education program at a Midwest university in the US. No return rate was provided. Students were provided the opportunity to complete the survey online and during class sessions. There were 81 female and 50 male participants with the majority (33\%) being enrolled as elementary education majors. The following demographic 
variables were obtained from each student: gender, age, major, stage in the teacher preparation program, future school level, and autism workshop attendance.

This correlational study used the Autism Attitude Scale for Teachers (AAST) developed by Olley, DeVellis, DeVellis, Wall, and Long (1981) to assess pre-service teacher attitude toward children with autism. The AAST provides seven items on a 5point Likert scale with ratings from 1 (strongly disagree) to 5 (strongly agree). Teachers were encouraged to rate each item based on their beliefs and not according to how they felt they should believe. Surveys were distributed via email or handed out during class sessions. All responses were kept anonymous. Data analysis included descriptive statistics, correlations, and ANOVAs. Tukey post hoc comparisons were made. Results noted that pre-service teachers had high levels of positive attitudes towards children with autism with higher scores related to items that were associated with the teachers' influence on the child. They also demonstrated high scores for items related to the inclusion of children with autism into the public school setting. Demographic variables were noted to correlate with attitude. Pre-service teachers majoring in special education were more positive than those in the regular education program. Female preservice teachers had more positive attitudes than their male counterparts. Pre-service teachers with teaching and working experience with children who have autism had more positive attitudes than those pre-service teachers who only had indirect contact with children with autism.

This study provides valuable information for teacher preparation programs that are charged with the responsibility to train teachers to become infective instructors to our increasingly diverse student population within the US. Understanding factors and/or 
characteristics that might play a part in determining the attitude of a teacher can be extremely important when updating these important programs.

This section summarized studies that assessed pre-service teacher's attitudes toward the inclusion of students with disabilities. The majority of studies analyzed the effect of special education coursework on the attitude of the pre-service teacher toward the inclusion of students with autism. Most noted a positive effect of such coursework on the attitudes of the pre-service teacher. Understanding the attitudes of pre-service teachers can provide important information to guide future teachers. This may entail improvements in teacher preparation programs to allow for additional training in the general area of special education and students with disabilities. This may be essential as teachers continue to enter the educational arena where the number of children with disabilities continues to rise. The next section focuses on teachers who are already in the field of education teaching students with disabilities. Their attitudes towards students with disabilities included in the general classroom are assessed.

\section{Teachers}

Elliot (2008) measured teacher attitude toward inclusion by comparing the practice and success levels of students with and without disabilities in physical education. Participants included 20 elementary physical education teachers with a range of 2-25 years of teaching experience. The study compared students with mild to moderate mental disabilities to students without disabilities. Students with more severe disabilities and physical disabilities were not included.

Selective sampling included utilizing the PEATID-III questionnaire to measure teacher attitude toward inclusion. This questionnaire consisted of 12 statements rated on 
a 5-point Likert scale ranging from 1 (strongly disagree) to 5 (strongly agree). The questionnaire had prior evidence of reliability and validity with a Cronbach alpha of .88 for the total scale. The Physical Educators' Attitude Toward Teaching Individuals with Disabilities - Third Edition (PEATID-III) was mailed to the school address of all elementary physical education teachers in the school districts, which gave prior consent to researchers. Once questionnaires were returned, investigators reviewed them and chose 20 teachers -10 with positive attitudes toward inclusion and 10 with negative attitudes toward inclusion. Student selection included consent from parents and then matched-subject design was used to ensure that students with disabilities were matched with students without. They were matched on gender, age, and skill level of assessed physical education skill.

In this correlational study, data collection included observations of teachers while teaching the class with the included student with a disability and his/her matched peer. The students were observed and two things were recorded: (a) each practice trial and (b) whether each trial was a success according to the teacher's definition. These were recorded using a systematic observational checklist. Data analysis included percentages that were recorded on each identified student for each practice trial and to denote teacher recognition of success of skill out. A mixed ANOVA design was used to determine simple and main effects.

Results revealed no significant interaction between teacher attitude and type of student disability. Teacher attitude, however, did influence the number of practice attempts for students. A main effect for teacher type (positive attitude versus negative attitude) was noted. Students taught by teachers with a positive attitude toward inclusion 
were given significantly more practice attempts $(M=8.2 / \mathrm{min})$ than students taught by teachers with a negative attitude toward inclusion $(M=4.7 / \mathrm{min})$. There was a main effect for student type (disability versus no disability). Students with disabilities had significantly fewer practice attempts $(M=4.55 / \mathrm{min})$ than students without disabilities ( $M$ $=8.35 / \mathrm{min})$. When the amount of successful practice attempts was analyzed, students taught by teachers with positive attitudes had higher successful practice attempts (80\%) than those students taught by teachers with negative attitudes $(67.5 \%)$.

This study provides useful information for self-evaluation for teachers within this study. It provides excellent data to support a need for additional teacher training in the area of inclusion. Understanding the need to provide teachers with support and professional development training to encourage positive attitudes toward inclusion is essential for school districts when implementing inclusive programs. This study highlights the importance of a positive teacher attitude toward students with disabilities as they are increasingly included into the general education population.

Cook and Cameron (2010) measured teacher concern and rejection toward students with disabilities. The researchers hypothesized that teachers in an inclusive setting would base their concern or rejection of students based on their beliefs about that student's disability. Participants were taken from a selection of schools in northeastern Ohio that were nominated for this study by a district level administrator as an elementary school with multiple inclusive classrooms. Of the 19 targeted schools, $16(84.2 \%)$ participated. Of the 102 inclusive teachers in these schools, $65(63.7 \%)$ chose to participate in this study. Sixteen percent of the student population for this study included students with the following disabilities: learning disability (40.1\%), cognitive disability 
(23.4\%), attention-deficit disorder (10.6\%), behavioral disorder (10.1\%), multiple disorders (4.8\%), autism (3.2\%), orthopedic disability (2.1\%), hearing impairment (2.1\%), visual impairment (1.6\%), and other health impairment $(1.1 \%)$.

In this correlational study, data collection included the Basic Scale of Disability Severity (BSDS) which allows teachers to rate students as either having mild or severe disabilities. The BSDS measures student characteristics in three domains: (a) intellectual functioning, (b) behavior, and (c) motor/sensory and communication skills. The BSDS is based on a 4-point Likert scale ranging from mild to severe disability. The reliability of the BSDS was assessed by the second author and a graduate student. They rated a randomly selected sample of the population (46\%) on two separate occasions. Cohen's kappa estimated an overall agreement $(k=.81)$ between raters.

Data analysis included two separate ANOVAs to estimate the effect of student type of disability on teacher concern/rejection ratings. Students labeled learning disabled, cognitive disabled, attention-deficit disorder, and behavioral disorder were compared as well as nondisabled students. Scheffe post hoc tests were also used.

Scheffe post hoc analyses revealed nondisabled students received significantly lower concern ratings than students with learning disability $(p<.001, \mathrm{~d}=.84)$, cognitive disorder $(p<.001, \mathrm{~d}=1.04)$, attention-deficit disorder $(p<.01, \mathrm{~d}=.86)$, and behavioral disorder $(p<.01, \mathrm{~d}=.78)$. There were no significant differences between teachers' concern ratings for these groups of students with disabilities. Scheffe post hoc analyses noted rejection ratings for nondisabled students were significantly lower in comparison with students with learning disability $(p<.001, \mathrm{~d}=.52)$, and behavioral disability $(p<$ 
$.001, \mathrm{~d}=.80$ ). Students with behavioral disability were noted to get significantly higher ratings than those with cognitive disorder $(p<.01, \mathrm{~d}=.79)$.

This study provides insight into teachers' overall ratings toward students with disabilities within the regular classroom. This study will be valuable to administrators within these Ohio school districts as they are implementing inclusive based classrooms within their school districts. Understanding which types of disabilities cause increased teacher concern can allow for increased support with that student population. This will help with teacher attitude toward inclusive practices that include students with more severe disabilities.

Levins, Bornholt, and Lennon (2005) investigated the attitudes of teachers toward students with special learning needs. There were four main goals identified: (a) examine the effects of the teachers' personal experiences with special educational needs on attitudes; (b) examine the effects of professional experience on attitudes specifically attitudes of pre-service and in-service teachers; (c) explore the attitudes toward students with specific needs such as a learning disability, ADHD, or hearing impairment; and (d) look at the components of attitudes that relate to the teacher's behavioral intentions which contribute to behavioral actions. The participants included a group of third-year undergraduate pre-service teachers enrolled in a class on special education $(n=45)$ and a group of experienced teachers enrolled in a university in-service program to retrain as special education teachers $(n=32)$ in Australia. The pre-service teachers were noted to be younger and both groups were predominately female. The in-service group's teaching experience ranged from 2-15 years. Both groups had teachers with personal experience with someone with special needs. 
In this descriptive design, data collection included multiple surveys to examine teacher attitude, cognitive components, affective components, and behavioral intentions. Teacher attitude was examined through a "memory test" where the teacher was provided with four similar stories relating to a student going to high school. Each teacher was provided with the same story at random with the student identity changed each time (e.g., a child with ADHD, a child with moderate intellectual disability, a child with a physical disability, and a child without a disability). Ratings were compared from the 11 positive, 12 neutral, and 11 negative items.

The cognitive component was measured from a 26 -item inventory using a 7 -point Likert scale. The affective components were examined via a series of four stories given about a situation regarding a student with $\mathrm{ADHD}$, a physical disability, a learning disability, or special needs followed by a prompt "How do you feel right now about what's happening in the story?" Finally, the behavioral intentions were measured on 7point Likert scale, which included positive actions, negative actions, and intentions to gain experience. The following demographic information was collected also: family background, age, gender, years of teaching experience, personal experience with a friend or family member with special needs, and previous in-service training for ADHD. No reliability or validity statistics were provided for any of the inventories.

Results revealed that personal and professional experience did not seem to be a factor in attitude toward students with special needs. Having been around students with special needs did not seem to alter attitude significantly. Attitude as it related to cognitive, social, or physical needs of the child were also assessed. Attitudes toward students with cognitive needs were noted to be more positive than toward children with 
physical needs. Attitudes toward children with social needs were less positive. When teachers' thoughts were assessed in relation to behavioral intentions, results indicated that there was not a link between implicit thoughts and intentions to act toward students with special needs. However, it was noted that positive thoughts were linked with intentions to positive actions and negative thoughts were linked to negative actions. Negative thoughts were linked with teachers' intentions to gain more experience with students with special needs. Feelings of guilt were noted as linked with intentions to act negatively (Levins at al., 2005).

This study provides some clear implications for teachers in training regarding students with special needs. This study highlights the fact that teachers' thoughts about children with special needs and their feelings of guilt do play a part in their actions toward those children. Understanding teacher attitude and then providing in-service training or undergraduate coursework to optimize the positive attitude of teachers will be most beneficial for students with special needs.

Soodak, Podell, and Lehman (1998) assessed teacher responses to inclusion of students with disabilities into their classrooms. The following research questions were examined: (a) What are the nature and dimensions of teachers' affective responses to including a child with disabilities in their general education classrooms? (b) How do teacher attributes and beliefs, student characteristics, and school climate relate to teachers' responses to inclusion? and (c) How well do these factors predict teachers' responses to inclusion? Participants were recruited three different ways. First, within the New York metropolitan area, teachers enrolled in graduate courses were asked to participate. Next, all teachers (regular and special education) within the local universities 
were asked to participate. Finally, researchers distributed survey packets to teachers within local schools. Of the 530 total teachers given survey packets, 188 were returned for a return rate of $35 \%$.

This quasi-experimental study used four surveys to obtain data. The Response to Inclusion Survey was designed to provide hypothetical scenarios to teachers in which they had to indicate whether they were accepting or opposing to inclusion of the described student. The student disabilities described in this survey included hearing impairment, learning disability, mental retardation, behavior disorder, or a physical handicap requiring a wheelchair. Two separate scales were found with the Response to Inclusion Survey: hostility/ receptivity and anxiety/calmness. Cronbach's alpha noted adequate reliability with .92 and .87 . The Teacher Efficacy Scale was used to measure teacher's beliefs about their own efficacy and that of their teaching methods $(\alpha=.79)$. The Differential Teaching Survey was used to measure time engaged in specific teaching practices. Teachers rated frequency on a 6-point scale $(\alpha=.81)$. The School Climate Survey assessed responses related to school conditions and school climate. Test-retest reliability coefficients ranged from .45 to .66 for each statement.

Data analysis included factor analysis to determine reliability of the two scales (hostility/ receptivity and anxiety/calmness) as well as interactions. Regression analyses were performed using each as a dependent variable. Independent variables included the hypothetical disability, school climate variables, self-reported engagement of differentiated teaching, teacher efficacy, years of experience, and number of student with disabilities in the current class. Tukey tests and post hoc Scheffe comparisons were also used. 
When considering the first research question, results revealed two separate emotional responses identified by teachers relating to inclusion: hostility/receptivity and anxiety/calmness. Hostility/receptivity was related to teacher enthusiasm of including a student with a disability and expectations of the experience. Anxiety/calmness noted the emotions related to the teacher having the student with a disability within the classroom. With regard to the second question, findings suggested that teachers were most influenced by type of student disability. Teachers were more hostile towards having to include students with learning disabilities, mental retardation, or behavior disorders. Of these disabilities, teachers are only anxious about the inclusion of students with mental retardation. They were fearful toward the inclusion of students with physical handicaps.

An interesting finding was that teachers became less receptive to inclusion of students with learning disabilities as they acquired teaching experience. Findings noted that teachers who used differentiated instruction and who rated themselves as having high teaching efficacy were more likely to be receptive of inclusion. Teachers with a sense of low teaching efficacy were found to be hostile toward inclusion (regardless of their use of differentiated instruction). When personal efficacy of teachers was assessed, teachers with a greater sense of personal efficacy were less anxious and hostile toward inclusion.

Finally, the third question addressed how well the factors chosen for this study could predict teacher response to inclusion. The hostility/receptivity of teachers toward inclusion accounted for $43.6 \%$ total variance. The anxiety/calmness of teachers toward inclusion accounted for only $19.8 \%$ of the total variance which means there may be other factors relating to this dimension. 
This study highlights the complexity of how teachers think about inclusion. The study suggests that, if discovered, many dimensions relating to teachers' hostility and anxiety regarding inclusion can be changed. The experience level of the teacher was directly related to the teacher's acceptance of inclusion and teacher attitude correlated to specific disability type. Understanding such correlations could provide insight for specific teacher training, which is essential for school districts that are attempting to integrate inclusive practices.

Similarly, Lanier and Lanier (1996) examined the effects of teacher experience on the teacher's attitude toward inclusion and noted different results. This study assessed the teacher's willingness to include a student with a disability was measured using a survey form that allowed teachers to rate specific scenarios. Participants included twenty-two teachers who took the course "Identification and Education of Exceptional Students in the Regular Classroom" at Georgia Southern University between September 1987 and December 1991. No survey return rate was provided.

In this pre-post design, data collection included a survey that provided specific scenarios that the teachers rated. The survey was given at the completion of the "Identification and Education of Exceptional Students in the Regular Classroom" and again after at least three years of teaching. The survey contained 60 classroom scenarios that were rated on a 5-point Likert scale by teachers. Responses included the following ratings: 1) I feel I could handle such a student in my regular classroom without any fundamental change in my present procedures; 2) I feel I could handle such a student in my regular classroom, provided advice from a specialist or consultant was occasionally made available whenever I felt a need for such aid in dealing with a particular problem; 
3) I feel I could handle such a student in my classroom, provided there was a full-time specialist available at my school who could provide frequent consultation for me and supplementary training for the student; 4) I felt that such a student would benefit most by being assigned to a special class or school; 5) I feel that such a child cannot be handled profitably within the context of regular or special public education.

The ratings from the initial administration were compared with the scores from the final administration to measure response change. Elapsed median time was five years between administrations of the survey. No reliability or validity scores were provided for scale. The independent variable in this study was teacher attitude toward including students with special needs into the regular education classroom. The dependent variable was the teaching experience. Data analysis included using ratings from the pre-and postassessment to formulate a response change score.

Results revealed that of the scenarios provided, less than $1 \%$ were viewed as inappropriate for the public schools (rating $=5$ ). There were $12-13 \%$ of teachers who rated scenarios as needing special education within public schools (rating $=4$ ). Ratings that received a four or five were noted to be scenarios about students with severe or profound disabilities. Eighty-six percent of the scenarios were rated by teachers as being appropriate for the regular education classroom (rating $=1-3)$. Teachers $(47 \%)$ were noted to have minimal change as a result of teaching experience. When ratings were changed they were equally divided between optimistic (25\%) changes and pessimistic $(25 \%)$ changes.

This study emphasizes the importance of educating teachers about students with disabilities. This study highlights the notion that teaching experience does not seem to 
make a difference for most teachers when acceptance of students with disabilities is concerned. This highlights the need to continue research on this topic for a more complete understanding of specific characteristics or factors related to successful inclusion.

Monahan and Marino (1996) evaluated the attitudes of South Carolina teachers toward inclusion. The researchers hypothesized that greater support via in-school services, resources, and teacher preparation would elicit more positive attitudes toward inclusion. Participants were randomly selected teachers throughout South Carolina. Three hundred and forty-two surveys were returned for a response rate of $94 \%$.

This descriptive study used a survey to elicit responses regarding 25 statements about inclusion. The survey was based on a 5-point Likert scale that rated responses from strongly agree to strongly disagree. The survey addressed the following areas: regular education teachers (role, attitudes, and knowledge); collaboration and team teaching; special education (role and resources); students (rights, performance/skills and perceptions); and families. No reliability and validity statistics were provided for the survey. Data analysis included computation of percentiles based on each area of the survey.

When examining the role of regular education teachers, results revealed an overall consensus $(72 \%)$ that inclusion would not be successful because of the excessive resistance from regular education teachers. Seventy-five percent of participants indicated that regular education teachers do not have the appropriate instructional skills or educational background to teacher students with disabilities. Over half of the participants (67\%) reported that regular education teachers prefer to send students with disabilities to 
special education classrooms for instruction instead of staying in the regular classroom. In the area of collaboration, many of the participants (84\%) were in favor of collaboration for students with disabilities.

When considering the role of special education teachers, only a little more than half of the participants (57\%) indicated that special education teachers provided support for all students and that the necessary resources are available for inclusion to be successful. However, $51 \%$ felt that even with redistribution of special education resources into the regular education classroom, there would not be a decrease on the instructional demands of the regular education teachers. When looking at student performance, a substantial number of participants $(62 \%)$ indicated that inclusion of students with disabilities would not negatively impact the learning of regular education students. However, $68 \%$ of the participants stated that students with disabilities had improved social skills when placed within the regular education classroom and 55\% felt that regular education peers were accepting of students with disabilities. Overall, $62 \%$ of participants felt that students with disabilities benefit from inclusion; yet, $71 \%$ felt that those students require more attention and assistance than can be provided by the regular education teacher. The area of families was inconclusive as to whether parents are supportive or non-supportive of inclusion.

This study emphasizes that teacher attitude toward inclusion may be positive yet there is still a great need for additional classroom support when regular education teachers are asked to implement inclusion. This study will provide valuable information to schools for professional development ideas to enhance teacher supports when faced with an inclusive classroom. 
Leatherman (2007) examined the perspectives of teachers regarding inclusion in their own words. The specific research questions presented were (a) How does a teacher perceive her inclusive classroom? and (b) What are the factors or resources associated with a successful inclusive classroom from the teacher's point-of-view? Participants were eight teachers in an inclusive early childhood classroom within the southeastern part of the United States. Purposeful convenience sampling was used for teacher selection. The author had a previous association with each participant through the local university as a graduate teaching assistant. The following were common characteristics of participants: (a) teachers had taught for at least one year in an inclusive classroom and did not have a degree in special education, (b) teachers expressed a feeling of success with inclusion, and (c) teachers reported positive experiences with inclusion. All participants were female with ages ranging from 26-61years. Six were Caucasian and two African American.

This qualitative study used an open-ended interview to gather data. Open-ended interviews were used with the following prompts: (a) Tell me about working with the children in your classroom, (b) Tell me how you have made the classroom successful for all children, and (c) Whom do you turn to for support? Participants' interviews were audio recorded and the researcher asked for clarification when answers were vague or unclear. The interview length ranged from 30 to 90 minutes. Data analysis included verbatim transcription of each interview. Member checks were completed to assure reliability and validity of the interview. The interviews were read and re-read to familiarize the researcher with the data. Information was separated into meaningful units of data and labeled. Themes and categories were presented. 
Results revealed five main themes: (a) great places for children and teachers, (b) the need for training or workshops, (c) positive experiences foster success, (d) support from administrators, peers, and therapists, and (e) decision to make classrooms inclusive. The first theme, great places for children and teachers, was based on the teacher's positive attitudes toward inclusive classrooms. One teacher noted - "You have challenges but you have 10 times more rewards." Teachers reported feeling that their participation within an inclusive classroom made them a better teacher. One teacher who said "I just see all children as children" summed up most of these teachers' feelings toward students with disabilities. The second theme, the need for training or workshops came from six of the teachers expressing the need for more education on inclusion. Each expressed the need to have more training or workshops related to the education of students with disabilities. The third theme, positive experiences foster success, was attributed to teacher feelings of past success with students with disabilities. One teacher noted “...it really has to do with your previous experience with people with disabilities. If those have been very positive experiences, I think you are more willing to try and learn." A second teacher noted what it takes to make it work "...it takes hard work to get there; it takes planning, lots of ingenuity to figure out what to do. The more I do myself, the more I see it can be done. Three years ago you would not have sold me on it. Now, I have decided yeah...It works well."

The fourth theme, support from administrators, peers, and therapists, highlights all eight teachers' feelings about the success of inclusion. One teacher stated "I definitely think administrative support is important and them being able to listen to you and maybe give you strategies and ideas." Another teacher noted "we had a lot of support from his 
therapists. We had a lot of support and help I think that was crucial." Each teacher reported experiences of support from administrators, peers, or therapists that were helpful to them with their inclusive classrooms. The final theme, decision to make the program inclusive, was noted from two teachers who indicated that the decision to make their classroom inclusive was made by administration without their input. One teacher noted "I don't think we were considered but we were told we are doing this." The other stated "It was kind of discussed...It's coming here. Then you find out we are going to do this. So why should I reject? I know we are going to do this. All I can do is try this." This study examines the perceptions of how teachers perceive inclusion. The qualitative data derived from this study can be used to improve existing inclusive programs as well as implement others. The detailed accounts provided by these eight teachers can elicit valuable conversation among teachers and administrators when designing or improving an inclusive educational program.

Short and Martin (2005) examined the perceptions of rural high school students and general and special education teachers toward inclusion. The study provided the following research questions: (a) To what extent do students (with disabilities and those without disabilities) feel that inclusion is beneficial to them? What do they see as the benefit? (b) To what extent do teachers (both special education and general education) feel that inclusion is beneficial to the school setting? What do they see as the benefits? (c) To what extent are attitudes different between the group of students and teachers? Participants included students with disabilities $(n=29)$ and general education students ( $n$ $=43)$ attending a rural Midwest state high school. The general $(n=13)$ and special $(n=$ 
7) education teachers from that same high school also participated in the study. The return rate for the survey was $100 \%$.

In this qualitative study, data collection included observations, surveys, and interviews. Three sets of observations were completed within both types of classrooms (inclusion classroom versus no inclusion). Additionally, observations took place in special education classrooms that contained only special education teachers and students. Personal interviews with open-ended questions were also used. Questions were taken from the literature review for the study. An open discussion about inclusion was also a part of the interview process. The interview protocol consisted of the following questions: (a) What benefits do you receive by being put in an inclusionary classroom? (b) Do you feel inclusion is always beneficial? Why or why not? (c) Do you think you should be part of the decision-making process regarding inclusionary classrooms? (d) What can teachers do to make their classrooms more comfortable for all students? and (e) What can cause your attitude to change (positive or negative) in a classroom? These questions were modified according to the group interviewed. The survey consisted of a 5-point Likert scale rating perceptions of benefits for inclusion ranging from 1 (disagree) to 5 (strongly agree). Mean scores were reported.

Data analysis included coding of the interview data with triangulation to further enhance the validity of the research. A principal component analysis of the survey responses was completed to ensure the above-mentioned Cronbach alphas. Once the data were entered, an ANOVA was completed with post-hoc multiple comparison tests as needed. 
Findings revealed that the highest average rating for most groups (general and special education students and special education teachers) regarding the benefits of inclusion was socialization $(M=3.91)$. General education teachers rated socialization as one of their lowest benefits of inclusion $(M=3.20)$. All four groups, general education students $(M=3.20)$, students with disabilities $(M=3.10)$, general education teachers (M $=2.90)$, and special education teachers $(M=3.33)$ rating feeling comfortable in the inclusion classroom as one of their lowest benefits. Additionally, students with disabilities $(M=2.85)$ indicated that teachers did not always make them feel comfortable in the inclusive classroom. There was a significant difference between the special education teachers' positive view of inclusion compared to the other groups' views.

The interviews presented major themes regarding benefits of inclusion: (a) learning more and (b) losing the benefit of smaller classes. The first theme learning more was illustrated via a special education student's interview: "I get more benefits when I'm in other classes because you get to see and learn just like the rest of the kids your age and don't get treated like you don't know how to do the same work as the rest of the kids." A special education teacher stated, "I often observe my kids just sitting in class not participating." Finally, a special education teacher reported, "All the kids in my class regardless of disability are expected and do participate."

The second theme that emerged, losing benefit of smaller classes, was highlighted by statements from students with disabilities, such as: “No, being in regular classes isn't always good. Cuz some teachers only help the one who they really like or that makes good grades and the larger classes left you out." A special education teacher noted, "I don't feel like I get to do as much with the kids as I did when we had a small self- 
contained room." Finally, a general education teacher indicated that inclusion "allowed for meeting more kids" and "let those kids learn like the rest of us."

When looking at attitudes toward inclusion, all groups were found to rate involvement regarding the decision for inclusion as most important. The data revealed that the student with disabilities $(M=2.96)$ and the special education teacher $(M=2.00)$ felt that the student with disabilities was not always fully accepted by the general education teacher. When analyzing the interviews in relation to attitudes toward inclusion, three themes emerged: (a) teachers who care and are accepting; (b) too large of classes are distracting; and (c) involvement in the decision-making process.

The first theme, teachers who care and are accepting, was reinforced by the following statement from a student with disabilities: "The teachers help you feel good about your work." A special education teacher stated, "I wish I had the power to select which teacher had my children. There are some more open to kids with problems than others." The second theme, too large of classes are distracting, included a statement from one general education student: "Keeping the classes down helps. Less people do better and too many distractions can cause me to get in trouble even though you might like the people." The last theme, involvement in the decision making process, was reinforced by a statement from a student with disabilities: "Yes I should be involved because of my age and because we know what we can and can't do."

This study provides excellent detailed accounts of a rural high school in the Midwest regarding inclusion of students with disabilities. These data will be valuable to administrators looking to improve inclusion practices within this school as well as administrators within any district across the United States. This information is very 
valuable to any person working with students who have disabilities. It allows for very personal insight into the lives of teachers (general and special education) and students (general and special education).

Jobe and Rust (1996) investigated the attitudes of general education teachers toward inclusion in the public schools in the United States. The design of the study was correlational. The research question examined four background characteristic variables to assess their potential relationship with teacher attitude. The assessed variables were gender, teaching experience, special education teaching experience, and inclusion inservice training. Participants were randomly selected teachers in the database of Market Data Retrieval in Chicago, employed in general education schools in the United States. Of the 500 total surveys sent, 162 were usable surveys for a return rate of $32 \%$ from 44 states. States not represented were Alaska, Maryland, Rhode Island, South Dakota, Vermont, and Wyoming. Forty-five participants were male and 117 were female. Seventy-two teachers reported in-service training on inclusion and 29 had special education teaching experience.

This correlational study utilized the Opinions Relative to the Integration of Students with Disabilities (ORI) survey to assess teacher attitude toward inclusion of students with disabilities in the regular classroom. Teachers provided gender, teaching experience, special education teaching experience, and inclusion in-service training along with the survey. The ORI had a 6-point Likert scale that rated responses ranging from strong agreement to strong disagreement. The ORI provided a total score and four factor scores. The four factors were as follows: Factor $1=$ Benefits of Inclusion; Factor $2=$ Inclusion Classroom Management; Factor 3 = Perceived Ability to Teach Students with 
Disabilities; and Factor $4=$ Special vs. Inclusion General Education. An alpha reliability coefficient was calculated for the total score and four factors: Total score $(25$ items $)=$ $.90 ;$ Factor $1(8$ items $)=.88$; Factor $2(10$ items $)=.68$; Factor $3(3$ items $)=.76$; and Factor $4(4$ items $)=.78$

Data analysis included analysis of variance, factor analysis, and Pearson's correlation coefficients. Mean scores were employed for factor analysis using SPSS-X defaults. Four factors were found with Eigen values of 9.20 (Factor 1), 1.84 (Factor 2), 1.64 (Factor 3), and 1.22 (Factor 4). These were consistent with previous findings and the ORI scoring manual. Pearson correlation coefficients were calculated using the total score, the four factors, and all demographic variables.

Results revealed that gender was not a factor for teacher attitude toward inclusion when looking at the ORI Total score. A significant difference was noted with gender and Factor 3 (perceived ability to teach students) and Factor 4 (special versus inclusion general education). Males had a higher perceived ability to teach students with disabilities than females and were slightly more positive toward inclusion. Teaching experience (including special education) of the teacher did not make a notable difference in teacher attitude. There was no significant difference between the attitudes of teachers based on teaching experience. On the contrary, inclusion in-service training was noted to be significantly related to Factor 1 (benefits of inclusion) and Factor 2 (ability to teacher students with disabilities). Teachers were noted to be slightly more positive toward inclusion if they had previous inclusion in-service training.

Overall, data analysis indicated almost exactly neutral attitudes of teachers toward inclusion. Teachers noted (in the margins of the protocols) that the type of disability 
would be a factor. Teachers reported that they would be more eager to make accommodations for physical disabilities versus cognitive, emotional, or behavioral disabilities. This study provides insight for potential in-service training or workshops for teachers to ensure that they are prepared to include students with varied disabilities into their classrooms. Specifically, the results provide target groups for in-service training such as those teachers working with students who have cognitive, emotional, and behavioral disabilities.

Bender, Vail, and Scott (1995) examined correlations between teacher background, instructional strategies or class variation, and attitude toward inclusion (favorable versus less favorable). Participants comprised general education teachers $(N=$ 127) of grades one through eight taken from 11 of 12 schools in three large school districts in northeastern Georgia. Participant demographics included 10 men, 117 women, 115 Whites, 9 African Americans, and 3 were noted as other race. Most of the participants held Bachelor's degrees (60\%), 37\% had a Master's degree, and a few (3\%) had more advanced degrees. Most held elementary education certification $(n=113)$ with the remainder having provisional or emergency certification. The researchers noted that Georgia requires each certified teacher to take at least one course in special education during their teacher training.

In this quasi-experimental study, data collection included a six-question, 5-point Likert scale that ranged from 1 (strongly disagree) to 5 (strongly agree). The scale assessed the teacher attitudes/beliefs relating to benefits of mainstreaming for students with disabilities. A test-retest reliability correlation provided acceptable reliability for the questionnaire $(r=.81, p<.0001)$. The Teacher Effectiveness Scale is a 16-item Likert 
rating scale used to assess teacher effectiveness producing two different subscale scores. The reliability coefficients for both subscales were .78 and .75 respectively. The Bender Classroom Structure Questionnaire is a 40-item Likert rating scale used to measure teachers' use of instructional strategies. It provides three separate scores with reliability coefficients of $.88, .84$, and .74 , respectively.

Data analysis included calculation of mean scores to compare teacher attitude and instructional strategies. Based on obtained scores, teachers were placed into one of two groups: less positive attitude toward mainstreaming (Group 1) and more positive attitude toward mainstreaming (Group 2). A series of $t$-tests were used to make comparisons of the two groups based on characteristic variables which included years of teaching experience; years of teaching students with disabilities; number of students with disabilities; courses taken on students with disabilities; number of students in class; and household income. Lastly, three separate ANOVAs were used to compare the groups with scores from the Bender Classroom Structure Questionnaire (Total BCSQ, Individualized Instruction, and Cognitive Strategy Instruction).

Results presented several conclusions. Teachers were not using all strategies that have been proven to facilitate achievement for students with disabilities. Teachers were using relatively minor modifications for these students and were reluctant to implement more substantive adaptations. Teachers who reported having a more positive attitude toward mainstreaming (Group 2) were likely to be more consistent with the use of effective mainstreaming strategies than those with a less positive attitude toward mainstreaming (Group 1). There was no significant correlation between the teachers' perceptions of their own efficacy and their positive attitude for mainstreaming. If teacher 
perception of self-effectiveness was overall positive, it did not mean that the teacher was disposed to a positive outlook regarding mainstreaming. Teachers who had more students with disabilities in their classes were found to have better overall attitudes toward inclusion. Likewise, teachers who had more courses in the education of students with disabilities were more positive toward inclusive practices as a whole. These findings can provide valuable insight into analyzing the complex relationships between teacher attitude, background, and other variables and mainstreaming. The results from this study can positively influence teacher-training programs.

Van Reusen, Shoho, and Barker (2000) investigated whether background characteristic variables affected the attitudes of high school teachers toward inclusion of students with disabilities. The assessed variables were years of teaching experience, professional responsibility, gender, type of teacher training preparation (traditional versus alternative), amount of special education training, and content area taught. Participants were selected teachers employed in a large suburban high school in San Antonio, Texas. Of the 191 total teachers surveyed, 125 responded for a return rate of $65 \%$.

In this quasi-experimental study, data collection included a two-part survey used to measure teacher attitude toward inclusion. The first section elicited background variables. The second part consisted of a 20-item, 4-point Likert scale ranging from strongly disagree to strongly agree that assessed teacher attitude toward inclusion. This scale measured teacher attitude over four domains: (a) preparation in serving special populations, (b) academic climate, (c) academic content/teacher effectiveness, and (d) social adjustment. No reliability or validity statistics were provided regarding the survey. 
Analysis of variance and independent $t$-tests were used to determine relationships between characteristic variables and teacher attitude toward inclusion $(p<.05)$.

Results revealed some interesting correlations relating to the amount of special education training. No significant relationship was noted between teacher attitudes and the other characteristic variables in this study. A significant difference was noted between those teachers who reported high levels of special education training and those that reported no or little special education training. Teachers with more special education training displayed an overall positive attitude toward teaching students with disabilities. A significant difference was noted between two of the four domains and the teachers level of special education training. Teachers with high levels of special education training had a more positive attitudinal response toward academic content/teacher effectiveness and teacher preparation. Teachers with higher levels of special education training had significantly better attitudes towards inclusion than those with no or minimal special education training. The authors note that more than half (54\%) of teachers at the high school level reported negative attitudes towards the inclusion of students with disabilities into their classes.

This study emphasizes the importance of providing teachers with adequate special education training if they are asked to include students with disabilities into their regular classroom. This study provides insight into the attitudes and beliefs about inclusion that are essential for administrators trying to implement inclusive practices within their school districts.

Grider (1995) highlighted the perspective of teachers, parents, and school administrators regarding the highly controversial topic of inclusion within the educational 
system. The study provided insight into the lives of parents, teachers, and administrators who were touched by inclusion. Participants included two parents, three teachers, and two principals from a small school district. Participants were chosen because the interviewer knew them personally or professionally and good rapport had been established.

In this qualitative study, data collection included interview sessions conducted by the researcher that were tape-recorded and transcribed for analysis. The participants were provided with a copy of the interview questions one week prior to their scheduled interviews. They were also provided with a letter describing the purpose of the interview, an informational sheet defining full inclusion, and a summary of both proponents' views on full inclusion and opponents' views on full inclusion. The following open-ended questions were asked: (a) What is your reaction to the points made by those in favor of full inclusion? (b) What is your reaction to the points made by those against full inclusion? (c) Which position do you think is the most practical to use in your school system? (d) What would you tell lawmakers in your area who are currently debating this issue? and (e) What are your final thoughts on the subject? The researcher provided no data analysis details.

Findings revealed that no one in the present study supported full inclusion. Each of the parents, teachers, and administrators indicated that there should be a continuum of placement options for students to capitalize on individual student strength. The participants in the current study stated that full inclusion would be a violation of P. L. 94142 and would be unfair to special needs students as well as unfair in some cases to students without disabilities. Participants were adamant that full inclusion could not meet 
the needs of all students with disabilities. Each emphasized the need to have a continuum of placement options for students with disabilities.

This study highlights the need for an approach that might encompass both inclusion and collaboration along with pullout services to meet individual student needs. It also provides valuable insight into the lives of parents, teachers, and administrators who work with these students on a daily basis and have valuable information to give.

Cook, Semmel, and Gerber (1999) examined the attitudes of principals and special education teachers toward the inclusion of students with mild disabilities. Participating schools were chosen from a School Environment Project (SEP) questionnaire that was investigating the effects of school environments on performance and self-esteem of students with mild disabilities included within the general classroom during the school day. Participants were taken from a stratified random sample of 1,126 urban and suburban schools in two southern California counties. Fifty-seven total schools ( 33 elementary and 24 junior high) agreed to participate. Of the 57 principals provided a questionnaire, there were 49 completed and returned (85.96\%). A questionnaire was also given to one randomly selected special education teacher within each participating elementary school. Twenty-nine special educators completed and returned the survey $(87.87 \%)$. Two randomly selected special education teachers in each junior high school were given questionnaires. Thirty-five returned the completed survey $(72.91 \%)$.

In this correlational study, data collection included the SEP questionnaire. The questionnaire included 21 statements about the inclusion of students with mild disabilities from the Regular Education Initiative Teacher Survey (REITS). This survey had reported 
a previous mean item reliability coefficient of .87 for the 61 items on the original survey and a Cronbach alpha of .82 for the 14 factors derived from the survey. The SEP questionnaire included the highest-loading items that represented attitudes toward inclusion sufficiently. The SEP questionnaire included a Likert scale where participants could choose a rating ranging from 1 (strongly disagree) to 5 (strongly agree).

Data analysis included descriptive statistics to analyze and present data. Univariate means and standard deviations were calculated to report the attitudes of principals and teachers toward inclusion. Nonparametric bivariate procedures (MannWhitney U-tests) were used to determine differences between principals and special educators on 7 items from the questionnaire. Finally, a multivariate discriminate function was also used to further analyze these differences.

Results indicated significant differences between principals and special education teachers with regard to inclusion. Many more principals (63\%) supported the statement Students with mild disabilities improve academic achievement when placed in the general education classroom with consultation services - than special education teachers (27\%). A second area of differences between principals and special education teachers dealt with special education resource allocation for students with disabilities included in the general classroom. The concern is highlighted given requirements and pressure from high-stakes testing and the notion that administrators may see inclusion as a way to funnel special education resources toward higher achieving students who would be more likely to improve overall test scores. The majority of special education teachers (75.51\%) reported strong agreement with the statement - Mandated instructional resources should be protected for students with mild disabilities regardless of setting - while few principals 
$(32.65 \%)$ rated this statement as strongly agree. Over half of principals (51\%) and most special education teachers $(69 \%)$ were in agreement that regular education teachers do not have the training or skills to meet the needs of students with mild disabilities within the regular classroom. Even with this conclusion, the majority of principals (63\%) rated inclusion as the most effective placement choice for students with mild disabilities and $78 \%$ of the principals believed that the achievement of students with disabilities would increase with inclusion.

This research provides valuable insight for California district administrators as they look at inclusion within their district. Principals and special education teachers obviously have very different opinions when considering inclusion of students with mild disabilities. This information will be essential for guidance in preparing supports for these inclusive programs. This research also highlights the fact that although principals appear to understand the skill deficit of the regular education teacher, they still believe students with mild disabilities will flourish in an inclusive environment.

Daane, Beirne-Smith, and Latham (2000) investigated the attitudes of administrators, elementary general education teachers and special education teachers toward inclusive education. The study was conducted in a mostly rural school district in the Southeast that comprised approximately 8,000 students where inclusion had been implemented for the past two years. The teachers and administrators in this district had received no training on inclusion. Participants included administrators $(N=15)$, elementary regular education teachers $(N=324)$, and special education teachers $(N=42)$ within the district (participant selection criteria and return rate were not provided). 
In this qualitative study, data collection included a 24-item, Likert survey with a 4-point scale ranging from 1 (strongly disagree) to 4 (strongly agree). The inclusion inventory assessed the following: (a) teacher collaborative efforts, (b) instruction of students with disabilities, (c) teacher preparedness for meeting the needs of students with disabilities, and (d) perceived achievement outcomes of students with disabilities. A semi-structured interview was conducted with four general education teachers, four special education teachers, and four administrators. The general and special education teachers were selected randomly from the participating schools. The administrator from each of the chosen general education teacher's school was interviewed. The interview questions were developed by the researchers to correspond with the four categories on the survey. Specific data analysis information was not provided.

Findings revealed overall agreement among administrators, general education teachers, and special education teachers regarding their views of the inclusive education efforts within their schools. The three groups were in agreement that there are currently cooperative efforts within their schools relating to inclusion. The groups agreed that students with disabilities maintain the right to education within the regular classroom and did recognize the social benefits for such students. They maintained, however, that many students with disabilities could not receive an effective education within the inclusive classroom. Administrators and teachers disagreed about the effects of students with disabilities on classroom management. Both groups of teachers postulated that there were increased classroom management problems when students with disabilities were placed in the general education classroom; however, administrators did not feel this way. 
These results may be attributed to the administrator's lack of direct involvement with the inclusive process. The study highlights the importance of general education teachers, special education teachers, and administrators working closely with one another when implementing an inclusive process within a school. It provides a basis for professional development for schools with regards to inclusive practices for teachers and administrators.

This section highlighted studies that assessed teacher attitude toward inclusion of students with disabilities within the regular education classroom. Some provided comparisons of educator and administrator attitude toward inclusion noting differences among teachers and administrators (Daane et al., 2000; Grider, 1995). This provides insight into the differences and similarities of these two distinct populations who have the shared responsibility to educate students who have disabilities. Understanding differences between these two populations can be important when implementing inclusive practices within a school district. Successful inclusion hinges on team work among teachers and administration. The next section provides studies that focus primarily on administrator's attitudes toward inclusion of students with autism. Understanding the role that administrator's attitude may influence successful inclusion within a school is important.

\section{Administrators}

Praisner (2003) surveyed principals of elementary schools to assess attitudes toward inclusion of students with disabilities. The study focused on the following research questions: (a) What are the attitudes of elementary principals toward the inclusion of students with severe/profound disabilities in the general education setting? 
(b) What is the relationship between the principals' personal characteristics, training, experience, school characteristics, and their attitudes toward inclusion? and (c) What is the relationship between principals' perceptions of appropriate placements for students with different types of disabilities and their attitudes and experiences? Participants were elementary principals randomly chosen from the Commonwealth of Pennsylvania. Of the 750 surveys mailed, 408 were returned ( $54 \%$ return rate). The participating principals were from schools that enrolled K-6 students of varying size (250 to over 1000 students). Many of the schools (47.1\%) reported 6\%-10\% special education population with differing degrees of inclusion.

In this correlational study, data collection included the Principals and Inclusion Survey (PIS), which is a four section inventory that included (a) demographics, (b) training and experience, (c) attitudes toward inclusion, and (d) principals' beliefs about most appropriate placement. The demographics section of the PIS assessed school demographics. It consisted of two questions that asked the number of total student population and average class size. An additional two questions asked for the total number of students with disabilities in the building and how many were included in regular education classrooms for at least $75 \%$ of the school day. The second section gathered data on potential variables that might influence principal attitude toward inclusion. The assessed variables included (a) age, (b) gender, (c) years of full-time regular education teaching experience, (d) years of full-time special education teaching experience, (e) years as an elementary school principal, (f) number of special education credits in formal training, (g) number of in-service hours in inclusive practices, (h) certification in special education, (i) number of relevant content areas in formal training, 
and (j) personal experience with an individual with a disability outside school settings. Principals were asked if they had a mission statement that addressed inclusion and a plan for crisis intervention for students with special needs. Validity for this section was addressed through a panel of four experts that reviewed the questions. A review of the literature on inclusion also was used to develop potential variables.

The third section included the Superintendent's Attitude Survey on Integration (SASI) that was used to measure principal attitude toward students with profound or severe disabilities. This survey consisted of a 10-item questionnaire based on a 5-point Likert scale ranging from strongly agree to strongly disagree. A reliability coefficient of .89 was reported for this section along with a validity check through a panel of experts. The last section was used to measure the principals' perception about placement for students in different disability categories. For each disability category, the principal chose one of the following placement options: (a) special education services outside the regular school, (b) special class for most of all of the school day, (c) part-time special class, (d) regular education class instruction and resource room, (e) regular education class instruction for most of the day, or (f) full-time regular education with support. This section was based on the available options and categories that were identified under the Commonwealth of Pennsylvania as defined by the Individuals with Disabilities Education Act (IDEA). Data analysis included descriptive statistics to analyze and present data, and to inspect relationships among variables. Frequency distributions and percentages were calculated for each variable. Central tendency data and a Pearson-Product Moment Correlation or Point-Biserial Correlation also were computed to determine relationships within the data. 
The first research question looked at principal attitude toward inclusion of students with special needs. Data analysis revealed that that $21.1 \%$ of the principals were positive about inclusion; $2.7 \%$ were negative; and $76.6 \%$ were uncertain (yet skewed more toward a positive attitude). Interestingly, principals were noted to be more favorable toward inclusion when it was presented as voluntary rather than mandatory. The second research question explored the relationship between principals and various variables that might influence attitude toward inclusion. Significant correlations $(p=.05)$ were found indicating that the principals who had experiences with individuals who have disabilities were more positive toward inclusion. Also, the number of in-service training and special education credits taken by the principal positively influenced attitude toward inclusion.

The last research question compared principal placement perceptions about students with different types of disabilities and their attitudes and experiences. Principals were found to choose options for students with disabilities within the regular education setting the majority of the time (59.9\%) and special education services outside the regular education classroom the least (6\%). Principals were noted to choose the least restrictive placement in the regular classroom most often for the disability categories of speech and language impairment (93.7\%), physical disability (87.4\%), other health impairment (84.9\%), specific learning disability (81.9\%), deaf or hearing impairment (71.9\%), and blind or visual impairment (71.9\%). They chose this placement less frequently for serious emotional disturbance (20.4\%) and autism (30.1\%). When principal experiences were analyzed in relation to disability categories, serious emotional disturbance was the only category that had a significant amount of negative experience (51.4\%). 
This study improves the understanding of principals' attitudes toward students with disabilities. Highlighted from this study is the importance of principal attitude toward inclusion of students with disabilities as it may negatively alter the placement of students with disabilities.

Sharma and Chow (2008) investigated whether background variables of principals affected their attitudes toward integrated education. The study addressed the following research questions: (a) What are the attitudes of Hong Kong primary school principals toward the integration of students with disabilities in the mainstream classroom? (b) What is the relationship between the professional and background variables of principals and their attitudes toward integrated education? The design of the study was correlational. The assessed variables were age, gender, years of teaching experience, number of years as a school principal, experience with family member or friends with a disability, average class size, and qualifications in educating students with disabilities. Participants were chosen from a pre-selected target sample using a stratified random sampling procedure of the 719 public and private primary schools in Hong Kong. Of the 360 total principals surveyed, 130 responded for a return rate of $36 \%$.

This study used a two-part survey to measure principal attitude and collect demographic data. The first part consisted of the School Principals' Attitudes Toward Inclusion (SPATI) scale, which is a 30-item, 5-point Likert inventory that ranged from strongly disagree to strongly agree. The reliability coefficient for the inventory was reported by Bailey (2004) at .92 with 639 respondents. The second part asked for demographic information from each principal. Data analysis included mean scores and standard deviations for each item on the SPATI scale. 
Overall, results revealed that principals' attitudes toward integrated education were slightly negative. There was a significant relationship between principal experience with family member or friends with a disability and positive attitude toward integrated education. Years of teaching experience and student enrollment were found to have a negative effect on principal attitude toward integrated education.

This study highlights areas of potential in-service training or workshops for principals to ensure that they are prepared to include students with disabilities into their buildings. This study provides the Hong Kong education bureau with information to enhance integration of students with disabilities into regular classrooms.

Horrocks, White, and Roberts (2008) examined principal attitude toward inclusion of students with disabilities and the relationship those attitudes have on placement recommendations for students with autism. The study also assessed how demographic variables affect attitude toward inclusion and placement decisions of principals. The design of the study was qualitative. Specific demographic variables measured were school level, gender, years of experience as principal, years with the district, formal training in special education, experience serving children diagnosed with autism, belief that children with autism could be included, personal experience, and overall experience with inclusion. Participants included public school principals in Pennsylvania. A stratified random sample that included all principals in Pennsylvania was used to identify potential participants for the study. The sample was stratified by school (elementary, middle, and high) and community (urban, suburban, and rural). The Lawsche-Baker test of proportional similarity was conducted to ensure the sample represented the population of Pennsylvania. Overall, the sample represented the total 
population. Of the 1,500 total principals surveyed, 571 responded for a return rate of $38 \%$.

This study used The Principal's Perspective Questionnaire that consisted of four parts. The first part assessed the personal and professional characteristics of the principal. The second part measured placement decisions of the principal as related to the inclusion of students with autism. The third part measured overall principal attitude toward inclusion using 17 questions specific to inclusion. The last part measured attitude toward inclusion along with special education. Part two of the questionnaire yielded Cronbach Alphas for the placement scores from pre- and post-tests ( $\alpha=.62$ and .71$)$. Part three of the questionnaire produced Cronbach Alphas of .87 and .89. Data analysis included mean scores for overall mean attitude score based on responses from part three of the questionnaire. An ANOVA was conducted on each of the variable characteristics using both scale means to assess links between attitudes and variables.

Results revealed that overall principals had a positive attitude toward inclusion in general. Years of experience as principal, experience serving children diagnosed with autism, and having the belief that students with autism could be included were found to have significant correlations with positive principal attitude toward inclusion of students with autism. The principal characteristics of school level, gender, years with the district, formal training in special education, personal experience, and overall experience with inclusion were not significantly related to attitudes of these principals. This study highlights areas of potential in-service training needed to provide principals with knowledge related to students with autism and inclusion. 
Barnett and Monda-Amaya (1998) surveyed principals of elementary, junior high, and high schools in the state of Illinois to assess their attitudes toward inclusion of students with disabilities. The study focused on the following research questions: (a) How do principals define inclusion and to which populations of students do they apply that definition? (b) What attitudes do principals have toward inclusive education? (c) What leadership approaches do principals most commonly exhibit? (d) Does leadership approach influence how they define and react to the philosophy of inclusion? and (e) What is the extent of use and perceived effectiveness of activities and educational practices that are viewed in the literature as important for successful inclusion programs? Of the 115 surveys sent to principals in elementary, junior high, and high, 65 (57\%) were returned. Thirty-three (56\%) were from elementary schools, $16(59 \%)$ were from junior high schools, and $16(55 \%)$ were from high schools.

In this correlational study, data collection included a four-section survey instrument. The first section gathered information regarding the principal and the school. The second section addressed the leadership approach used by the principal. Four statements that summarized four common models of school leadership were provided and the principal was asked to choose one.

The third section looked at the principals' definition of inclusion. Principals were provided with terms (derived from a review of the literature on inclusion) and were asked to choose five that they considered most essential to the definition of inclusion. The principals chose from a list of special needs populations that they thought their definition of inclusion would apply. The categories were the following: learning disabilities, atrisk for school failure, behavior disorders, educable mentally handicapped, trainable 
mentally handicapped, severely or profoundly handicapped, physically or health impaired, and culturally diverse. Finally, the principals responded to a 4-point Likert scale, ranging from 0 (not at all) to 3 (completely), to statements in relation to the following: (a) their attitudes toward inclusion, (b) the degree of inclusiveness of their school, (c) the extent to which their school was working toward becoming inclusive, (d) how well prepared their teachers were for implementing inclusion, (e) whether they felt inclusion could work in their schools, and (f) whether the school community was supportive of inclusion.

The last section of the survey provided a place for principals to rate the extent to which 21 different programs, activities, and strategies (derived from the literature) were being used within their schools and to what extent, if at all, they were effective. They rated each practice on a 3-point Likert scale ranging from 0 (never) to 3 (routinely). They rated the extent to which they perceived the practice to be effective on a 3-point Likert scale ranging from 0 (not at all) to 3 (extremely).

Data analysis included descriptive statistics to analyze and present data on the first three sections of the survey. Analyses of variance (ANOVAs) were used to determine differences among grade levels or personal characteristics of the principals. Differences between ratings of extent of use and perceived effectiveness of the 21 practices were obtained using $t$-tests. Correlations were used to evaluate potential influences of leadership approaches on inclusion, selection of student populations, ratings of educational practices, and attitude statements.

The first research question looked at the principals' definition of inclusion and to which populations do they apply that definition. Data analysis revealed no clear 
definition of inclusion among principals. The only descriptor identified by more than $50 \%$ of principals was supportive environment. The remaining descriptors were rated as essential by $50 \%$ or less of the principals. When data analysis of the principals' ratings of student populations was completed, misinterpretation and inconsistencies were found. Thirty-six percent of principals stated that students with moderate disabilities would fit within their definition of inclusion. Similarly, $20 \%$ of principals felt that students with profound or severe disabilities would fit their definitions. On the other hand, most principals felt that students with learning disabilities (97\%), educable mentally handicapped (73\%), and behavior disorders (72\%), those at risk for school failure (83\%), and those from culturally diverse backgrounds $(66 \%)$ would most likely fit with their definition of inclusion.

The second research question addressed the attitude of principals toward inclusion. This study provided no evidence of a correlation between positive or negative attitudes toward inclusion and the number of years of administrative experience or experience with special education. There was a low level of agreement $(M=1.29)$ with the statement all children should be educated in the regular classroom. This highlights the lack of agreement on their definition of inclusion and what populations they believe that definition applies.

The third research question focused on leadership approaches of the principals. According to the data, only $30 \%$ of the principals in this study chose the leadership statement that is most closely related to that advocated by proponents of inclusion. The last research question addressed educational practices deemed essential for inclusive settings. Principals rated the extent of use for these practices and their perceived 
effectiveness of them. Mean ratings noted three educational practices (heterogeneous or multi-age groupings, cooperative learning, and collaboration) that were rated highest by these principals. Conversely, the practices that received the lowest ratings (in-service on inclusion, interaction analysis, parent education or support groups, and peer coaching) were indicative of practices not used very often or that were ineffective for inclusion at their schools. No significant interactions were noted among grade levels or experience.

This research will be valuable in improving how schools are implementing inclusive practices. School districts can use this information to improve principal knowledge relating to inclusion and inclusive strategies or programs. Administrators play a significant role in structuring the instructional practices within the school. Increasing their knowledge base will benefit teachers who are directly influenced by the principal in their building.

This section provided important factors that may influence the attitudes of administrators towards inclusion of students with disabilities. Years of experience as principal, experience serving children diagnosed with autism, and having the belief that students with autism could be included were noted factors that influenced principal attitude in a study conducted in Pennsylvania (Horrocks, White, \& Roberts, 2008). Understanding these factors as they relate to principals will be important when trying to understand the relationship among teachers. The next section focused on the attitude of teachers toward the inclusion of students with the disability category of autism. It is of interest to determine the relevant factors and/or characteristics that may be important in the development of attitude (positive or negative) toward inclusion of this group of students within the regular education classroom. 
Teacher Attitude toward Inclusion of Students with Autism

Robertson et al. (2003) examined the relationship between general education teachers and children with autism in the regular education setting. Specifically, they evaluated the effect of the child's behavior along with inclusion within the classroom on the teacher-student relationship. The student's level of inclusion and the presence of a one-on-one paraprofessional were also considered factors.

Participants included 12 students with autism, classmates of those students with autism $(N=175)$, and 12 general education teachers from two urban middle-class school districts. Participants with autism were (a) identified with autism according to their IEP; (b) had a confirmed clinical diagnosis of autism from an independent evaluator outside the school district; (c) had a minimum Verbal or Full-Scale IQ of 70; and (d) enrolled in the general education classroom full-time. In this quasi-experimental design, data collection included teacher and student surveys. The independent variable in this study is the teacher perception of the relationship with the children with autism included in the regular education classroom. The dependent variables include the presence of a paraprofessional, behavior, and level of social inclusion that might influence that relationship. Factor Analysis was utilized along with simple mathematical comparisons to analyze data.

Findings revealed that teachers overall reported a positive relationship with included students with autism; however, as the behavior problems of the child increased, the quality of the relationship decreased. The study found that the quality of the teacherstudent relationship was related to the child's status within the classroom as rated by peers. Students were asked to list the names of students that hang around together in 
separate groupings. These ratings were analyzed by calculating a score for each student to determine social involvement within the classroom as perceived by their peers. As the social rating fell, the quality of the teacher-student relationship weakened. Finally, the study noted that the presence of a paraprofessional did not have an effect on the relationship between the teacher and student with autism included in the regular classroom.

These findings highlight a connection between the teacher and student with autism's relationship and the quality of their inclusion with classmates. It also denotes the complexity of the relationships among teacher, child, and peer characteristics, along with social environment. Understanding teacher attitude specific to autism highlights very important factors that can influence the successful implementation of inclusion for students with autism. Teacher attitude can have a negative or positive effect on student success (Elliot 2008); therefore, it is essential for school administrators and policy makers to understand that this relationship exists.

Kasa-Hendrickson and Kluth (2005) analyzed the experiences of five elementary education teachers as they taught students with non-verbal autism in an inclusive classroom. The study focused on the positive aspects of inclusion and what works for teachers who are successfully implementing the practice of inclusion.

Participants included five teachers and six students with non-verbal autism. Teachers were interviewed and included based on the following criteria: they saw the placement of the student with autism as permanent, they expressed their support and belief in inclusion, and they viewed non-verbal students with autism as competent students and included them in their classroom. Teachers also each had experience 
teaching regular and special education. Students were placed based on the following criteria: they were labeled autism and mental retardation, they had little or no verbal communication, and they used some form of sign language, picture symbols, or typing to communicate. Each of the students had been included in the regular education setting since preschool. Participants attended a classroom from one of two elementary schools in a diverse, mid-size urban city in the United States.

This qualitative study utilized formal interviews with each teacher monthly for the first three months and bi-monthly thereafter. The researchers acted as participant observers in each classroom for approximately two hours. The constant comparative method was utilized throughout data collection and analysis.

Findings revealed that these teachers were deemed successful given their willingness to see the nonverbal students with autism as active learners of the class. The desire of the teacher to create strategies for these students was evident. They saw inclusion as unconditional and were willing to utilize multiple adaptations to their classrooms. Students were not sent away because of behavior or academic struggles. These teachers saw inclusion as an opportunity for change and growth for their classrooms. They understood that inclusion of students with autism would develop over time as they worked and learned about the individual needs of the students. Essentially, these teachers had to establish a cooperative and caring community within their classroom that was comfortable and accessible to all while welcoming the struggles as a "vehicle for learning." This study provides valuable information to educators who are attempting to implement inclusive practices. Understanding what works for students who have non-verbal autism in the regular education setting from teachers who are successful 
with inclusion can provide a wealth of information. Teachers and administrators can use these teaching practices as a model for other teachers.

Finke et al. (2009) engaged regular education teachers who have classroom experience with students who require $\mathrm{AAC}$ in an online focus group. The goal of this study was to identify and understand strategies that have been used by these teachers for students who require AAC. Specifically, they gathered the following information from these teachers: (a) the supports needed for successful inclusion, (b) the benefits of inclusion, (c) the adaptations required to support inclusion, (d) the negative impacts of inclusion, (e) the barriers to successful inclusion, and (f) recommendations for other teachers, professionals, and school administrators who are involved in the inclusion of children with ASD who require AAC.

Participants were required to meet the following inclusion criteria: (a) being a general education teacher, (b) having included at least one child with ASD who requires AAC in their classroom, (c) working in a school district within the United States, and (d) having access to the Internet. Five elementary school general education teachers met inclusion criteria. They were female, aged 26-35 years old, held a BA or MA, and had varying experiences with inclusion.

This qualitative study utilized a focus group methodology. The focus group met via the Internet where Phorum was used. Phorum is a password protected software program that allows text-based discussions to be posted on various topics. The topics and questions were posted by the researchers. New topics were posted weekly and participants were asked to participate in the discussion on the site minimally once per week for 15 weeks. Data were saved to a word processing document and analysis 
procedures were conducted to analyze the data. Data were sorted and coded to produce themes and subthemes. Cohen's Kappa was calculated to determine reliability. An agreement of .83 was noted. A copy of the summarized results was e-mailed to each participant for review to verify accuracy.

Findings fell into four main themes that emerged from the data. The participants reported that there are benefits of inclusion for the child with ASD who requires AAC, their parents, their classmates, the teachers, and the school. Some benefits they reported were social and academic leadership skill development, becoming a more effective teacher, reduction in challenging behaviors, and that parents have access to a new social network. The second theme found was negative consequences of inclusion. Some examples include increased stress due to irregular routines, increased noise within the classroom, increased time needed for planning and preparation, and increased pressure from parents. Challenges to inclusion were the third overall theme that developed. This was described as the parent's fight to get the child with ASD included in the general curriculum, need for time, need for equal time for students, need for increased communication and social skills, and finding an appropriate curricular match for their child. The last theme was entitled supports for inclusion. It included topics like provision of generalization opportunities, positive attitude about inclusion, willingness to collaborate with other team members, knowledge of individual student needs, and willingness to help the student in the classroom.

Recommendations for individuals who are new to the inclusion process were offered. The common recommendations were (a) keeping lines of communication open, and (b) keeping a positive outlook on inclusion. These findings provide insight for 
teachers implementing inclusive educational practices and have little or no experience working with students who have ASD who require AAC .

Kosmerl (2011) investigated the beliefs of general and special education teachers about the inclusion of elementary students with autism. The study addressed the following research questions: (1) What were the differences between general education and special education teachers beliefs about including elementary students with autism? (2) What were the differences of general and special educators' responses on specific questions of the Autism Attitude Scale for Teachers? and (3) What resources and supports do general education teachers think they need for successful inclusion of students with autism and what supports do special education teachers think they can provide? Participants included 50 regular education teachers and 50 special education teachers from Berks, Chester, Lancaster, and Montgomery counties in Pennsylvania. The teachers were obtained via convenience sampling and were from both urban and suburban districts within these four counties.

This mixed methods study design used the Autism Attitude Scale for Teachers (AAST) developed by Olley, DeVellis, DeVellis, Wall, and Long (1981) and a researcher developed questionnaire. The AAST provides seven items on a 5-point Likert scale with ratings from 1 (Strongly disagree) to 5 (Strongly agree). The rating scale has Forms A and B. The researchers combined both Form A and B for the purpose of this research that provided a 14-item scale. The questionnaire elicited background and demographic information from each teacher. The survey along with the questionnaire were emailed to 97 general educators and 86 special educators. Once 50 respondents from regular educators and 50 respondents from special educators was received the 
survey collection was ceased. Responses were kept anonymous. The following data were obtained from each teacher: gender, age, urban versus suburban, and previous student with autism in class (yes/no). The majority $(89 \%)$ of respondents were female and most $(90 \%)$ had never had a student with autism in class. Data analysis included means, standard deviations, $t$-tests, ANOVAs, and frequency recording. Crosstabulation and chi-square analyses were completed on three questions from the AAST.

Results indicated in general both regular and special educators reported receptive beliefs about the inclusion of students with autism. It was noted that special education teachers are more receptive to the inclusion of students with autism in the general education classroom when compared with the regular education teacher based on their responses to the AAST. Open-ended questions provided by the researchers elicited responses from both regular and special education teachers that indicated a significant need for classroom support and professional development in order for them to be successful with inclusion of students with autism.

This study provides insight into the views of regular and special education teachers who are confronted with the demands placed upon them by the increasing placement of students who have autism within the regular education classroom. Assessing teacher attitude toward the idea of inclusive practices for students with autism is essential for policy makers and school administrators as these students are increasingly identified and transitioned into public school classrooms.

A similar study by Park and Chitiyo (2011) examined teacher attitudes towards children with autism. The purpose of the study was to (1) assess teacher attitude towards children with autism, (2) compare regular and special education teachers' attitudes 
towards children with autism, and (3) examine demographic variables and types of exposure that teachers had to children with disabilities to determine if they affect attitude. Participants comprised $127(40 \%)$ teachers from a small Midwest town that included five elementary schools, one middle school, and one high school. There were 115 female and 12 male participants with the majority $(83 \%)$ being elementary education teachers. The following demographic variables were obtained from each teacher: gender, age, role (regular education or special education), teaching experience, autism workshop attendance, school level, and type of exposure (to students with disabilities).

This correlational study also used the Autism Attitude Scale for Teachers (AAST) developed by Olley, DeVellis, DeVellis, Wall, and Long (1981) to assess teacher attitude toward children with autism. The AAST provides seven items on a 5-point Likert scale with ratings from 1 (strongly disagree) to 5 (strongly agree). Teachers were encouraged to rate each item based on their beliefs and not according to how they felt they should believe. Surveys were distributed via mail or during meetings. All responses were kept anonymous. Data analysis included descriptive statistics, correlations, and ANOVAs. Tukey post hoc comparisons were also made.

Results noted that teachers had overall positive attitudes towards children with autism with higher scores related to the inclusion of such students within public schools. Demographic variables were noted to correlate with attitude. Younger teachers had more positive attitudes toward students with autism. Elementary teachers were found to be more positive toward students with autism when compared to those at the middle and high school level. High school teachers were found to have the least positive attitude toward students with autism. When gender was assessed, females had more positive 
attitudes than males and older teachers (above age 56) were significantly less positive than their younger counterparts (20-35 years and 46-55 years). No relationship was noted with teaching experience, role (regular versus special education teacher), or type of exposure to children with disabilities. Workshop attendance was noted to be a significant factor if the teacher had attended multiple workshops when compared to teachers who had attended only one or none. Those teachers who attended multiple workshops were noted to have significantly more positive attitudes toward students who have autism. Participation in only one or no workshops was not noted to influence attitude.

This study provides valuable information for the school districts that participated with the study. Administration can use results to guide future planning for student and teacher placement as well as professional development. It is important that school districts recognize the needs presented by teachers who are faced with the daily challenges of working with students who have autism. Providing them with support and training in the area of autism can improve attitudes and thus make a positive difference for the student.

This section has provided studies focused on understanding teacher attitude specific to autism and highlights very important factors that can influence the successful implementation of inclusion for students with autism. Various studies noted teacher characteristics such as special education training, inclusion training, increased teaching experience and gender that have been found to influence teacher attitude toward inclusive practices for students with disabilities. The type and severity of disability can also alter teacher attitude toward inclusion of students with autism (Robertson et al., 2003). As evident with this review, there are only a few number of studies that focus specifically on 
students with autism. It is important to understand teacher attitude specific to the disability of autism as prevalence rates continue to increase and these students enter public education.

\section{Summary}

There has been significant progress in the identification and treatment of children who have autism since Leo Kanner first identified the disorder in 1943. Currently, we have an alarming rate of children being identified as having autism within the United States. According to current data, 1 in 88 children has autism (Centers for Disease Control, 2012). These children are enrolled in public schools and have a right to an education within the least restrictive setting which is the regular education classroom. Teachers and administrators are faced with providing an appropriate education to this diverse population of students alongside their non-disabled peers. Teachers are often given little input into such decisions and are usually not trained to accomplish such a task.

Pre-service teachers, teachers, and administrator's attitudes toward inclusion of students with disabilities are not considered yet they are expected to educate this population of students. Understanding how these educators perceive students with disabilities can provide a window of opportunity for change or insight into factors that may influence their attitudes or beliefs. Teacher attitude toward students with disabilities, including autism, play a significant role in the inclusion of these students (Park \& Chitiyo, 2010). Teacher attitude (negative or positive) can greatly influence the outcome for students with autism as they enter the classroom. The TATIS was developed to assess teacher attitude toward inclusion of students with disabilities. It was used in the 
present research to assess teacher attitude toward students with autism. Teacher attitude toward the inclusion of students with disabilities must be assessed and considered when attempting to implement inclusive practices within a public educational setting. Doing so will provide good information for providing the most appropriate services for students with autism. 
CHAPTER III

\section{METHODS AND MATERIALS}

This chapter describes the methods and materials used to conduct this correlational study and provides information about the population, instruments, procedure, data management and analysis.

This study was designed to answer the following research questions:

1. What are the attitudes of public school teachers toward inclusion of students with autism?

2. Are there specific teacher characteristics related to teacher attitude toward inclusion of students with autism?

3. Are there differences between regular and special education teachers' attitudes toward inclusion of students with autism?

\section{Participants}

The population for this study was regular education teachers and special education teachers employed within the Wilderness Trail Educational Cooperative (WTEC) in South Central Kentucky. The WTEC serves the following school districts in Kentucky: Adair County, Berea Independent, Campbellsville Independent, Casey County, Clinton County, Estill County, Garrard County, Lincoln County, Madison County, Model Lab, Monticello Independent, Russell County, Science Hill Independent, 
Somerset Independent, Taylor County, and Wayne County. All teachers within each district was elicited through an email to participate in the study. Teachers were required to be full-time regular or special education teachers who were teaching within one of the school districts for the 2011-2012 school year. This investigator requested the total number of certified teachers teaching within each district from the Kentucky Department of Education. The resulting total was 2,627 for the 16 school districts and all were provided the opportunity to complete a survey for this study. These teachers make up the purposeful population for this study.

\section{Instruments}

Two instruments were used to collect data for this study. These included a demographic questionnaire that was developed by this researcher and a modified version of the Teacher Attitudes Toward Inclusion Scale (TATIS, Cullen et al., 2010).

\section{Demographic Questionnaire}

A researcher-developed questionnaire was used to collect personal and professional characteristics of participants. For the present study, the demographic characteristics that were obtained included gender, age, degree status, years of teaching experience, national board certification, grade level currently teaching, having a close family member with autism, being personally acquainted with a person who has autism (not a family member), frequency of contact with a person who has autism, having a student with autism in class and the severity level of that student, being adequately trained to teach students with autism, and having formal training in autism. Such personal teacher characteristics have been identified as factors relating to attitudes of teachers in India toward individuals with disabilities (Parasuram, 2006). One additional 
item included on the demographic questionnaire asked teachers to identify themselves as regular education teachers or special education teachers. If the teacher selected special education teacher, he or she was asked to further specify collaboration teacher or resource/self-contained teacher. The data from this questionnaire were used, in part, to address the second and third research questions.

The Teacher Attitudes Toward Inclusion Scale (TATIS)

The TATIS, developed by Cullen et al. (2010) was used to address the first research question. The TATIS consists of 14 items and takes approximately 10 minutes to complete. Responses to items are based on a 7-point Likert scale ranging from 1 (Disagree Very Strongly) to 7 (Agree Very Strongly). The TATIS normative sample consisted of 252 teachers enrolled in classes at a private university in Connecticut. Results indicated that $37 \%$ taught at the elementary level, $19 \%$ at the middle or intermediate level, and 30\% high school level (14\% did not report grade level taught). Gender representation was noted as $64 \%$ female and $36 \%$ male. The majority of teachers held Bachelor's degrees (77\%) while 14\% held a Master's degree and 9\% reported a degree above the Master's level. The majority ( $82 \%)$ of the teachers reported little teaching experience (0-3 years).

Construct validity was confirmed through principal component analysis. This procedure revealed three factors that accounted for over $58 \%$ of the total variance. The three factors were: (a) teacher perceptions of students with mild to moderate disabilities (POS, 6 items), (b) beliefs about the efficacy of inclusion (BEI, 4 items), and (c) perceptions of professional roles and functions (PRF, 4 items). Content validity for the TATIS was assessed with the Cronbach alpha correlation procedure. The TATIS 
revealed an overall Cronbach alpha reliability coefficient of .821. The Cronbach alphas for the factors of POS, BEI, and PRF, respectively, are $.803, .863$, and .680 . Once completed, the TATIS is scored using a scoring sheet that provides factor and total scale scores that may be compared to normative standards. T-scores and percentile ranks are provided. Higher scores on the TATIS relate to higher levels of support for inclusion. Scores that fall within one standard deviation of the mean are considered average scores and would not be considered negative or positive. Scores that fall above one yet below two standard deviations are considered slightly negative or positive. The scores that fall outside three standard deviations are considered statistically significant for a positive or negative attitude toward inclusion (Cullen et al., 2010).

For the current study, the TATIS was modified slightly. The term mild to moderate disabilities throughout the TATIS was substituted with the term autism. The substitution only designated a specific disability instead of grouping all mild to moderate disabilities into one general category. To verify this substitution does not affect the norms a factor analysis and Cronbach alphas were computed and results were compared to results obtained on the original TATIS by Cullen et al. (2010).

\section{Procedure}

Approval was obtained from the Human Subjects Review Board at Western Kentucky University and the University of Louisville. Participants were assured of voluntary participation and that all collected data would be kept locked in this researcher's private office to ensure confidentiality. Participants were informed that they could withdraw from the study at any time. 
Participants were sent an email containing a brief description of the present study. If they choose to participate, they were provided with a link to access the study, which directed them to complete a demographic questionnaire and an adapted Teacher Attitudes Toward Inclusion Scale (TATIS). The study was presented electronically through Survey Monkey $^{\mathrm{TM}}$, which is a web based program. This program allowed the teacher to exit at any time during the survey if he or she chose to discontinue participation with the study. The teacher's voluntary entry into the survey program was considered to be the teacher's consent for study participation.

For an incentive to complete the survey, each teacher was given the opportunity to provide his or her contact information at the end of the survey to be placed in a drawing for an Apple iPad2. Teacher contact information was obtained through a separate link to ensure teachers that survey responses were not linked to their personal contact' information. A reminder email was made weekly by this researcher to encourage survey completion. Collection time consisted of one month, which allowed adequate time for teachers to complete the survey. A random drawing was held after data collection to determine the winner for the Apple iPad2.

\section{Data Management and Analysis}

All data were entered and verified by this researcher, and data were checked for errors and to ensure completeness. Errors or unclear responses were treated as missing data. Data analyses were conducted using the Statistical Package for the Social Sciences (SPSS) program. The first research question was intended to determine the attitudes of public school teachers toward children with autism. Descriptive data (e.g., means, TATIS Total score) from the participants' responses on the TATIS for the total sample 
were used to address this question. To answer the second research question, an analysis of variance (ANOVA) was used to identify relationships between teacher characteristics and attitude toward inclusion. Tukey's post hoc analyses were used when a factor provided three or more means to provide specific information on which means were significantly different from each other. The third research question determined if any differences existed between regular and special education teachers. An ANOVA was used to initially examine differences among the three teaching levels (elementary, middle, and high). Post hoc analyses were used and these are presented in the next chapter with survey results. All completed surveys were stored in a locked file within this investigator's private office. 


\section{CHAPTER IV}

\section{RESULTS}

\section{Demographic Data}

This correlational research study examined the relationship between the attitudes of public school teachers toward inclusion of students with autism into the general education classroom highlighting individual teacher characteristics that influenced attitude. This chapter presents the results of the study.

A list of teachers employed as full-time certified teachers within the Wilderness Trail Educational Cooperative (WTEC) district for the 2011-2012 school year was obtained from the Kentucky Department of Education. There were 2,627 full-time certified teachers from 16 school districts employed in the WTEC located in South Central Kentucky for the present school year. All teachers were asked to participate in the study. Each teacher received an email that included a brief description of the study and a link to the survey. The link allowed the teacher to access a demographic questionnaire and an adapted Teacher Attitudes Toward Inclusion Scale (TATIS) if they chose to participate in the study. A reminder email was sent weekly for a total of four emails sent to each teacher. There were 56 submissions where the demographic portion of the survey was partially completed yet the participant discontinued before completing the survey. These partially completed surveys were not used. A total of 636 surveys ( $24.2 \%$ return rate) were completed. 
Table 1 presents information regarding demographics of the sample. Research Question 3 examines the differences between special education and regular education teachers, so Table 1 lists the demographics for each type of teacher for the total sample. The majority of the participants (75.8\%) were regular education teachers. Of the $24.2 \%$ that identified themselves as special education teachers, $61.7 \%$ described their current position as a resource or self-contained teacher and $38.3 \%$ as collaboration teachers. Overall, the participants in this study were predominately female (85.4\%), which is typical for the state. According to data from the Kentucky Department of Education, $79 \%$ of teachers in Kentucky are female (Kentucky Department of Education, 2011). Almost half (49.1\%) of the participants reported that they were elementary teachers while the rest were roughly split between high school teachers (28.1\%) and middle school teachers $(22.8 \%)$.

With regard to teaching credentials, a relatively small percentage of participants (13.1\%) had only a Bachelor's degree. Less than half (37.4\%) of the participants reported having a Master's degree yet nearly half (49.5\%) indicated that they have an education beyond that of a Master's degree. A small percentage of participants (10.8\%) reported having National Board Certification. Data from the Kentucky Department of Education reported that only $4.9 \%$ of Kentucky's teachers have national certification (Kentucky Department of Education, 2011). As might be expected, almost two-thirds of the participants were between 30 and 49 years of age. Smaller percentages of participants were in the age ranges of 50-59 (17.9\%) and 20-29 (14.3\%). A very small percentage of participants (2.5\%) fell in the age range of $60+$ years. Five ranges of years 
Table 1

Participant Demographics

Regular Education Special Education $\quad$ Total

$\begin{array}{llllll}\mathrm{n} & (\%) & \mathrm{n} & (\%) & \mathrm{n} & (\%)\end{array}$

Gender

Males

$78(16.2)$

$15 \quad(9.7)$

$93(14.6)$

Females

$404(83.8)$

$139(90.3)$

$543(85.4)$

Degree

Bachelor's

$72(14.9)$

$11 \quad(7.1)$

$83(13.1)$

Master's

$182(37.8)$

$56(36.4)$

$238(37.4)$

Beyond Master's

$228(47.3)$

87 (56.5)

$315(49.5)$

Grade Level

Elementary

$225(46.7)$

87 (56.5)

$312(49.1)$

Middle

$118(24.5)$

$27(17.5)$

$145(22.8)$

High

$139(28.8)$

$40(26.0)$

$179(28.1)$

Age

20-29

$72(14.9)$

$19(12.3)$

$91(14.3)$

30-39

$150(31.1)$

$53(34.4)$

203 (31.9)

40-49

161 (33.4)

$51(33.1)$

$212(33.3)$

50-59

87 (18.0)

27 (17.5)

114 (17.9)

$60+$

$12 \quad(2.5)$

$4 \quad(2.6)$

$16 \quad(2.5)$

(continued) 


\section{$\underline{\text { Regular Education }}$ Special Education}

Total
n $\quad(\%)$
n $(\%)$
n $(\%)$

Teaching Experience

$\begin{array}{lrcr}\text { 1-5 Years } & 87(18.0) & 21(13.6) & 108(17.0) \\ \text { 6-10 Years } & 90(18.7) & 51(33.1) & 141(22.2) \\ \text { 11-15 Years } & 106(22.0) & 27(17.5) & 133(20.9) \\ \text { 16-20 Years } & 91(18.9) & 27(16.9) & 117(18.4) \\ 21 \text { Years or more } & 108(22.4) & 29(18.8) & 137(21.5) \\ \text { ational Board Certification } & & & \\ \text { Yes } & 44(9.1) & 25(16.2) & 69(10.8) \\ \text { No } & 438(90.9) & 129(83.8) & 567(89.2)\end{array}$


of experience were offered as choices on the survey and the percentage of teachers in each of those ranges was fairly equivalent. The percentages in each group only varied from $17.0 \%$ for those with 1 to 5 years of experience to $22.2 \%$ for those with 6 to 10 years of experience. Overall, the current sample was representative of teachers currently employed in Kentucky.

\section{Participants' Experiences with Autism}

Additional aspects of the teachers' personal and professional experiences with persons with autism, as well as their perceptions of training in the area of autism, were assessed as part of the demographic questionnaire. Results are presented in Table 2 for regular education teachers, special education teachers, and the total sample. When participants were asked if they had a family member with autism, most $(93.9 \%)$ indicated that they did not and slightly more than half (52.2\%) stated they were not personally acquainted with a person who has autism. Half of the participants $(50.2 \%)$ described their average frequency of contact with a person who has autism (other than students) as very rarely. The majority ( $72.5 \%)$ of respondents reported having a student with autism in their classroom at some point. Several teachers $(40.3 \%)$ had multiple students with autism with multiple severity levels of the disorder while only a few (8.0\%) only had students with a severe level of autism. Most respondents (75.5\%) reported that they were not adequately trained to teach students with autism with the majority $(77.0 \%)$ indicating that they had no formal training in autism beyond the basics (i.e., an overview of the definition or characteristics of autism). 
Table 2

Participants' Experiences with Students with Autism and Training on Autism

$\underline{\text { Regular Education }}$ Special Education $\quad$ Total
n $(\%)$
n $(\%)$
n $(\%)$

Family Member with Autism

\begin{tabular}{|c|c|c|c|}
\hline Yes & $26 \quad(5.4)$ & $13 \quad(8.4)$ & $39 \quad(6.1)$ \\
\hline No & $456(94.6)$ & $141(91.6)$ & $597(93.9)$ \\
\hline
\end{tabular}

Personally Acquainted

$\begin{array}{llll}\text { Yes } & 218(45.2) & 86(55.8) & 304(47.8) \\ \text { No } & 264(54.8) & 68(44.2) & 332(52.2)\end{array}$

Frequency of Contact

$\begin{array}{lcccc}\text { Daily } & 29(6.0) & 14 & (9.1) & 43(6.8) \\ \text { Weekly } & 62(12.9) & 28(18.2) & 90(14.2) \\ \text { Monthly } & 76(15.8) & 22(14.3) & 98(15.4) \\ \text { Very Rarely } & 248(51.5) & 71(46.1) & 319(50.2) \\ \text { Never (Not Applicable) } & 67(13.9) & 19(12.3) & 86(13.5)\end{array}$

Student with Autism in Class

$\begin{array}{lrrr}\text { Yes } & 325(67.4) & 136(88.3) & 461(72.5) \\ \text { No } & 157(32.6) & 18(11.7) & 175(27.5) \\ & & \text { (continued) }\end{array}$


$\underline{\text { Regular Education }}$

n $\quad(\%)$ $\underline{\text { Special Education }}$

n $\quad(\%)$

$19(12.3)$

33 (21.4)

$11 \quad(7.1)$

$73(47.4)$

Total

Severity Level of Autism

Mild

Moderate

$103(21.4)$

$26 \quad(5.4)$

Multiple Students/Levels $113(23.5)$

Adequately Trained

Yes

No

$90(18.7)$

$392(81.3)$

$66(42.9)$

$156(24.5)$

$88(57.1)$

$480(75.5)$

Formal Training

Yes

77 (16.0)

69 (44.8)

$146(23.0)$

No

$405(84.0)$
$102(22.1)$

$136(29.5)$

$37 \quad(8.0)$

$186(40.3)$

n $(\%)$ 
Technical Adequacy of the Modified TATIS

The TATIS is a relatively new instrument and was slightly modified for the present research. Specifically, the minor substitution of autism was made in place of the phrase, mild to moderate disabilities, throughout the survey. A factor analysis was completed on the current survey results as a method of evaluating the instrument and determining if the current factor structure remained the same as for the original instrument. The technical adequacy of the modified TATIS is found in Appendix A. The developers of the TATIS (Cullen et al., 2010) obtained three factors accounting for $58 \%$ of the total variance via principal component analysis with a sample of 252 respondents. Their names and abbreviations for the factors were: (a) teacher perceptions of students with mild to moderate disabilities (POS; items 1-6), (b) beliefs about the efficacy of inclusion (BEI; items 7-10), and (c) perceptions of professional roles and functions (PRF, items 11-14). For the current study's results, a factor analysis using Principal Axis Factoring and Oblimin with Kaiser Normalization revealed the same three factors that accounted for over $63 \%$ of the total variance.

In their original study, Cullen et al. (2010) obtained an overall Cronbach alpha reliability coefficient of .821 and Cronbach alphas of $.803, .863$ and .680 for the factors of POS, BEI and PRF, respectively. Internal consistency for the modified TATIS used in the current study was also assessed using the Cronbach alpha correlation. The modified TATIS revealed an overall Cronbach alpha reliability coefficient of .887 and the Cronbach alphas for the factors of POS, BEI, and PRF, respectively, were $.840, .829$ and .833. The modified TATIS reliability coefficients were very consistent with those obtained by Cullen et al. (2010) with the exception of the PRF factor. The Cronbach 
alpha for the PRF factor for the modified TATIS was markedly improved. A reliability estimate of .70 is considered an acceptable level for a research instrument with group data (DeVellis, 2003). The current reliability coefficients confirm that the items in each factor from the modified TATIS, as well as the overall instrument, are consistently measuring the identified constructs.

The original TATIS provided scoring procedures that allowed responses to be tallied to provide scores for TATIS Factor 1 (POS), TATIS Factor 2 (BEI), TATIS Factor 3 (PRF), and a TATIS Full Scale score. Scores for each factor are obtained by tallying the respondent's raw scores for the corresponding items while the Full Scale score is a sum of all 14 items. Because of the wording of items in Factor 2 (BEI), those items were reversed scored to allow for consistency in interpretation across the factors. The original TATIS materials included tables to convert raw scores to $\mathrm{T}$ scores and percentile ranks. T scores have a mean of 50 and a standard deviation of 10 . Oddly, the original TATIS had norms where higher raw scores resulted in lower $\mathrm{T}$ scores and the lower $\mathrm{T}$ scores indicated teachers' attitudes and beliefs were very supportive of inclusion for students with disabilities. Appendix B provides standard score conversion charts for each raw score obtained from the modified TATIS used in the present study. However, in order to provide more clarity and consistency as to what the raw and $\mathrm{T}$ scores mean, the tables are arranged so that higher raw scores result in higher $\mathrm{T}$ scores and the higher $\mathrm{T}$ scores suggest that the teacher's attitudes and beliefs are more supportive of inclusion for students with autism. Conversely, lower T scores on the modified TATIS are indicative of support for a more traditional service delivery model for students with autism. 
In comparing the means and standard deviations for the modified TATIS with the original TATIS, it was noted the current sample had higher raw scores for means than the original TATIS. For example, on the Full Scale score conversion chart, the mean was a raw score of 62 whereas the mean raw score on the original TATIS was 50 . The higher mean scores suggest the current sample of teachers either had more positive attitudes toward inclusion in general or that teachers hold more positive attitudes toward inclusion of students with autism than they do for students with mild to moderate disabilities (as assessed on the original TATIS). For the modified TATIS Full Scale score conversion chart, raw scores ranged from 28 and under at the $<1$ percentile to 97 and over at the $>99$ percentile. This is a much larger range than that provided by Cullen et al. (2010). They reported a range of 37 and under at the 99.9 percentile to 68 and over at the .1 percentile. Similar differences were noted with the conversion charts for the three separate factors when compared to the originals produced by Cullen et al. (2010). Raw scores obtained in the present study were broader with the modified TATIS producing a larger standard deviation. This suggests that there were more deviations from the mean (i.e., neutral response) for the current study; specifically, higher raw scores were obtained indicating more support for inclusion than with the original TATIS conversion charts.

Research Questions

Question 1: What are the attitudes of public school teachers toward inclusion of students with autism?

Results from the TATIS were used to answer this question. The TATIS consists of 14 items concerning teacher attitude toward inclusion of students with mild to moderate disabilities with responses measured by a Likert scale with the following range: 
$1=$ disagree very strongly, $2=$ strongly disagree, $3=$ disagree, $4=$ neither agree nor disagree, $5=$ agree, $6=$ strongly agree , and $7=$ agree very strongly. All 14 items were used to examine teacher attitude toward inclusion of students with autism.

The overall mean score and standard deviation for each item on the TATIS were calculated (Table 3). Mean scores for all items ranged from 3.03 to 5.33. A score of 4 would denote a neutral response (i.e., neither agree nor disagree). Numbers above 4 were in agreement with the item while those below 4 disagreed with the item. The wording for items 7 - 10 was reversed; therefore, the opposite would be true for ratings on those items (i.e., lower numbers indicates more agreement and higher numbers indicate more disagreement). Twelve of the fourteen items on the TATIS were noted to have mean scores that indicated teachers were supportive, if only mildly, of inclusion for students with autism. The highest mean scores of 5.03 and 5.33 were for items 12 and 13 , respectively. Both of these items were within the third factor (PRF) that measured teacher perception of professional roles and functions. The other two items in the PRF factor were also relatively high with 4.74 for Item 11 and 4.86 for Item 14. These higher mean scores for the items within the PRF factor indicate positive teacher attitude toward working as a team (regular education and special education) to meet the needs of students with autism. Items 2 and 3 were the only items with mean scores indicating disagreement with statements supportive of inclusion. The results from these two statements suggest that teachers are not as supportive of full inclusion practices and think separate classrooms should remain as an option to meet the educational needs for students with autism. 
Table 3

TATIS Item, Factor and Total Full Scale Means $(n=636)$

Mean

SD

1. All students with autism should be educated in regular

classrooms with non-disabled peers to the fullest extent possible.

2. It is seldom necessary to remove students with autism from regular classrooms in order to meet their educational needs.

3. Most or all separate classrooms that exclusively serve students with autism should be eliminated.

4. Most or all regular classrooms can be modified to meet the needs of students with autism.

5. Students with autism can be more effectively educated in regular classrooms as opposed to special education classrooms.

6. Inclusion is a more efficient model for educating students with autism because it reduces transition time (e.g., the time required to move from one setting to another).

7. Students with autism should not be taught in regular classes with non-disabled students because they will require too much of the teacher's time.

8. I have doubts about the effectiveness of including students with autism in regular classrooms because they often lack the academic skills necessary for success.

9. I have doubts about the effectiveness of including students with autism in regular classrooms because they often lack the social skills necessary for success.

10. I find that general education teachers often do not succeed with students with autism even when they try their best.

11. I would welcome the opportunity to team-teach as a model for meeting the needs of students with autism in regular classrooms.

12. All students benefit from team teaching; that is, the pairing 
Mean SD

13. The responsibility for educating students with autism in regular classrooms should be shared between general and special education teachers.

14. I would welcome the opportunity to participate in a consultant teacher model (i.e., regular collaborative meetings between special and general education teachers to share ideas, methods, and materials) as a means of addressing the needs of students with autism.

TATIS Factor 1 (POS, Perceptions of Students)

TATIS Factor 2 (BEI, Beliefs of Efficacy of Inclusion)

TATIS Factor 3 (PRF, Perceptions of Roles and Functions)

TATIS Full Scale

62.17

11.53

Note. Means for items 7-10 have not been reversed scored in this table. Lower numbers indicate more agreement with inclusion practices (e.g., a rating of 3.0 would be equivalent to a rating of 5.0 for all other items). 
As the mean scores were in the middle of the Likert scale, indicating neutral responses to all statements, further analysis was considered necessary. To provide more detailed descriptive data on the attitudes of public school teachers toward inclusion of students with autism, the percentage of responses for each level of agreement or disagreement for each item on the TATIS is provided in Table 4. Percentages for Items 1 through 10 were noted to skew toward the middle of the Likert range. Percentages for Items 11 through 14 (Factor 3, PRF) were skewed to the right, indicating more agreement for items relating to teacher perceptions of professional roles and functions as related to students with autism and inclusion.

As a way to further examine and synthesize participants' agreement or disagreement with the statements from the TATIS, responses were combined. That is, all ratings of Agree, Strongly Agree, and Agree Very Strongly were combined to indicate general agreement, while all ratings of Disagree, Strongly Disagree, and Disagree Very Strongly were combined to indicate general disagreement. One interesting finding from this type of analysis is that nearly all teachers (83.4\%) agreed that the responsibility for educating students with autism should be shared between regular and special education teachers. Most teachers were supportive of team teaching (63.4\%) and a consultant teacher model $(63.4 \%)$ as a way to meet the needs of students with autism. The majority of teachers (73.1\%) disagreed with the statement, Students with autism should not be taught in regular classes with non-disabled students because they will require too much of the teacher's time.

Although as a whole, teachers indicated they were supportive of meeting the needs of students with autism in the regular education classroom, most (68\%) were still 
Table 4

Percent of Agreement with each TATIS Item for the Total Sample $(n=636)$

$\begin{array}{lllllll}\text { DVS } & \text { SD } & \mathrm{D} & \mathrm{N} & \mathrm{A} & \mathrm{SA} & \text { AVS }\end{array}$

1. All students with autism should be educated in regular classrooms with non-disabled peers to the fullest extent possible.

$\begin{array}{lllllll}2.8 & 4.9 & 20.4 & 11.2 & 33.8 & 17.6 & 9.3\end{array}$

2. It is seldom necessary to remove students with autism from regular classrooms in order to meet their educational needs.

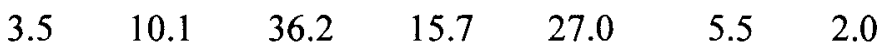

3. Most or all separate classrooms that exclusively serve students with autism should be eliminated.

$\begin{array}{lllllll}1.6 & 6.6 & 17.6 & 16.4 & 46.1 & 7.9 & 3.9\end{array}$

4. Most or all regular classrooms can be modified to meet the needs of students with autism.

5. Students with autism can be more effectively educated in regular classrooms as opposed to special educational classrooms.

6. Inclusion is a more efficient model for educating students with autism because it reduces transition time (e.g., the time required to move from one setting to another).

$\begin{array}{lllllll}2.8 & 6.8 & 22.8 & 29.6 & 29.7 & 6.1 & 2.2\end{array}$

7. Students with autism should not be taught in regular classes with non-disabled students because they will require too much of the teacher's time.

$\begin{array}{lllllll}11.5 & 15.4 & 46.2 & 16.0 & 8.2 & 1.3 & 1.4\end{array}$

8. I have doubts about the effectiveness of including students with autism in regular classrooms because they often lack the academic skills necessary for success.

$\begin{array}{lllllll}8.8 & 14.8 & 39.0 & 18.2 & 14.2 & 3.6 & 1.4\end{array}$


$\begin{array}{lllllll}\text { DVS } & \text { SD } & \text { D } & \text { N } & \text { A } & \text { SA } & \text { AVS }\end{array}$

9. I have doubts about the effectiveness of including students with autism in regular classrooms because they often lack the social skills necessary for success.

$\begin{array}{lllllll}6.9 & 13.5 & 35.1 & 17.9 & 20.6 & 3.6 & 2.4\end{array}$

10. I find that general education teachers often do not succeed with students with autism even when they try their best.

11. I would welcome the opportunity to team-teach as a model for meeting the needs of students with autism in regular classrooms.

$\begin{array}{lllllll}2.4 & 3.0 & 8.6 & 22.6 & 41.7 & 11.3 & 10.4\end{array}$

12. All students benefit from team teaching; that is, the pairing of a general and special education teacher in the same classroom.

$\begin{array}{lllllll}1.3 & 2.8 & 9.9 & 12.7 & 40.7 & 15.6 & 17.0\end{array}$

13. The responsibility for educating students with autism in regular classrooms should be shared between general and special education teachers.

0.9

14. I would welcome the opportunity to participate in a consultant teacher model (i.e., regular collaborative meetings between special and general education teachers to share ideas, methods and materials) as a means of addressing the needs of students with autism.

Note. DVS = Disagree Very Strongly $; \mathrm{SD}=$ Strongly Disagree $; \mathrm{D}=$ Disagree $; \mathrm{N}=$ Neither Agree nor Disagree; $\mathrm{A}=$ Agree; $\mathrm{SA}=$ Strongly Agree; AVS = Agree Very Strongly. 
in favor of the option of maintaining separate classrooms that exclusively serve students with autism. Almost half (49.8\%) indicated that it is necessary, at times, to remove students with autism from regular classrooms in order to meet their educational needs. Only a little more than half (57.9\%) of the teachers agreed that classrooms could be modified to meet the needs of students with autism.

Question 2: Are there specific teacher characteristics related to teacher attitude toward inclusion of students with autism?

An analysis of variance (ANOVA) was conducted to examine the scores for the three factors (POS, BEI and PRF) within the TATIS as well as the TATIS Full Scale score in relation to each of the variables of gender, age, degree status, years of teaching experience, national board certification, grade level taught, having a close family member with autism, being personally acquainted with a person who has autism (not a family member), frequency of contact with a person who has autism, having a student with autism in class and the severity level of that student, being adequately trained to teach students with autism, and having formal training in autism. Items 7-10 (Factor 2, BEI) were reversed scored prior to the analyses. When a statistically significant difference was noted for variables with more than two possible responses, a Tukey's HSD post-hoc test was performed to determine where the significant differences were occurring.

Table 5 presents the mean scores for each factor and the total Full Scale for all the individual teacher characteristics. Significant differences found through the ANOVAs and Tukey's HSD tests are noted in bold print within the table. Furthermore, superscripted numbers in the table indicate where the significant differences occurred within a characteristic. For example, a superscripted 1 indicates that variable is 
Table 5

Mean Scores for Teacher Characteristics on the TATIS

\begin{tabular}{|c|c|c|c|c|}
\hline & $\begin{array}{l}\text { Factor } 1 \\
\text { POS }\end{array}$ & $\begin{array}{c}\text { Factor } 2 \\
\text { BEI }\end{array}$ & $\begin{array}{c}\text { Factor } 3 \\
\text { PRF }\end{array}$ & $\begin{array}{c}\text { Total } \\
\text { Full Scale }\end{array}$ \\
\hline \multicolumn{5}{|l|}{ Gender } \\
\hline Males & 24.56 & 18.09 & 19.41 & 62.05 \\
\hline Females & 23.66 & 18.47 & 20.05 & 62.18 \\
\hline \multicolumn{5}{|l|}{ Age } \\
\hline 20-29 Years & 24.54 & 18.80 & $21.35^{1}$ & 64.69 \\
\hline 30-39 Years & 23.88 & 18.76 & 20.36 & 63.00 \\
\hline 40-49 Years & 23.52 & 18.19 & $19.21^{2}$ & 60.92 \\
\hline 50-59 Years & 23.32 & 18.01 & $19.35^{2}$ & 60.68 \\
\hline $60+$ Years & 25.50 & 17.56 & 21.19 & 64.25 \\
\hline \multicolumn{5}{|l|}{ Degree } \\
\hline Bachelor's & 23.94 & 18.70 & $21.31^{1}$ & 63.95 \\
\hline Master's & 23.40 & 18.26 & $19.67^{2}$ & 61.33 \\
\hline Beyond Master's & 24.06 & 18.45 & $19.82^{2}$ & 62.32 \\
\hline \multicolumn{5}{|l|}{ Teaching Experience } \\
\hline 1-5 Years & 24.12 & 18.87 & $21.11^{1}$ & 64.10 \\
\hline 6-10 Years & 23.82 & 18.67 & 20.43 & 62.93 \\
\hline 11-15 Years & 23.77 & 18.10 & 19.69 & 61.56 \\
\hline 16-20 Years & 23.94 & 18.56 & $19.19^{2}$ & 61.68 \\
\hline 21 Years or more & 23.41 & 17.96 & $19.48^{2}$ & 60.85 \\
\hline
\end{tabular}




\begin{tabular}{|c|c|c|c|c|}
\hline & $\begin{array}{c}\text { Factor } 1 \\
\text { POS }\end{array}$ & $\begin{array}{c}\text { Factor } 2 \\
\text { BEI }\end{array}$ & $\begin{array}{c}\text { Factor } 3 \\
\text { PRF }\end{array}$ & $\begin{array}{l}\text { Total } \\
\text { Full Scale }\end{array}$ \\
\hline \multicolumn{5}{|c|}{ National Board Certification } \\
\hline Yes & 24.57 & 18.78 & 19.91 & 63.26 \\
\hline No & 23.70 & 18.37 & 19.96 & 62.03 \\
\hline \multicolumn{5}{|l|}{ Grade Level } \\
\hline Elementary & 24.02 & 18.70 & 20.16 & 62.88 \\
\hline Middle & 24.08 & 18.56 & 20.17 & 62.81 \\
\hline High & 23.16 & 17.79 & 19.44 & 60.39 \\
\hline \multicolumn{5}{|c|}{ Family w/Autism } \\
\hline Yes & 24.82 & 19.97 & 20.18 & 64.97 \\
\hline No & 23.72 & 18.31 & 19.94 & 61.98 \\
\hline \multicolumn{5}{|c|}{ Personally Acquainted } \\
\hline Yes & 23.59 & 18.56 & 20.13 & 62.27 \\
\hline No & 23.98 & 18.28 & 19.81 & 62.07 \\
\hline \multicolumn{5}{|c|}{ Frequency Contact } \\
\hline Daily & 23.30 & $19.84^{1}$ & 20.93 & 64.07 \\
\hline Weekly & 24.50 & 18.62 & 20.81 & 63.93 \\
\hline Monthly & 24.05 & 19.19 & 20.50 & 63.74 \\
\hline Very Rarely & 23.91 & 18.27 & 19.68 & 61.85 \\
\hline Never (NA) & 22.59 & $17.13^{2}$ & 19.00 & 58.72 \\
\hline & & & & nued) \\
\hline
\end{tabular}




\begin{tabular}{cccc}
\hline Factor 1 & Factor 2 & Factor 3 & Total \\
POS & BEI & PRF & Full Scale \\
\hline
\end{tabular}

Student w/Autism in Class

$\begin{array}{lllll}\text { Yes } & 23.83 & 18.67 & \mathbf{2 0 . 2 5}^{\mathbf{1}} & 62.75 \\ \text { No } & 23.71 & 17.72 & \mathbf{1 9 . 1 9}^{\mathbf{2}} & 60.62\end{array}$

Severity Level of Student

$\begin{array}{lllll}\text { Mild } & 24.03 & 18.24 & 20.07 & 62.33\end{array}$

$\begin{array}{lllll}\text { Moderate } & 24.39 & 18.67 & 19.89 & \mathbf{6 2 . 9 5}^{1}\end{array}$

$\begin{array}{lllll}\text { Severe } & 21.35 & 17.05 & \mathbf{1 8 . 1 6}^{\mathbf{1}} & \mathbf{5 6 . 5 7}^{\mathbf{2}}\end{array}$

$\begin{array}{lllll}\text { Multiple Levels } & 23.80 & 19.24 & \mathbf{2 1 . 0 3}^{\mathbf{2}} & \mathbf{6 4 . 0 6}^{\mathbf{1}}\end{array}$

Adequately Trained

Yes

No

Formal Training

$\begin{array}{lllll}\text { Yes } & 24.54 & \mathbf{1 9 . 7 5}^{\mathbf{1}} & \mathbf{2 1 . 2 5}^{\mathbf{1}} & \mathbf{6 5 . 5 4}^{\mathbf{1}} \\ \text { No } & 23.57 & \mathbf{1 8 . 0 1}^{\mathbf{2}} & \mathbf{1 9 . 5 8}^{\mathbf{2}} & \mathbf{6 1 . 1 6}^{\mathbf{2}}\end{array}$

Note. Bolded items are statistically significant. Superscripts note items that are significantly different. Items in Factor 2 were reverse coded. POS $=$ Perceptions of students. $\mathrm{BEI}=$ Beliefs about the efficacy of inclusion. $\mathrm{PRF}=$ Professional roles and functions. 
significantly different from the variable with a superscripted 2 , but the variables with two superscripted $2 \mathrm{~s}$ are not significantly different from each other. Due to the large number of statistical analyses and the desire to minimize the risk of a Type 1 error, a more conservative $p$ value (i.e., $p<.01$ ) was adopted to determine significance. There were no significant differences for any of three TATIS factors or TATIS Full Scale score for the following teacher characteristics: gender, national board certification, grade level taught, having a family member with autism, and being personally acquainted with a person with autism.

Perceptions of professional roles and functions (PRF, Factor 3) provided the most differences when compared with individual teacher characteristics. A statistically significant difference was noted when Factor 3 was compared with seven teacher characteristics: degree status, $F(2,89)=4.99, p=.007$; age, $F(4,99)=5.64, p=.000$; years of teaching experience, $F(4,71)=4.03 p=.003$; having a student with autism in class, $F(1,141)=7.91, p=.005$; severity level of autism, $F(3,98)=5.95, p=.001$; adequate autism training, $F(1,258)=14.61, p=.000$; and formal autism training, $F(1$, $314)=17.86, p=.000$. However, some of the statistically significant differences found for these characteristics were specific to certain responses within the characteristic. For example, teachers with more teaching experience (16-20 years and more than 21 years) were statistically different than those teachers with less teaching experience (1-5 years). Similarly, there was a significant difference between younger teachers (20-29 years) and older teachers (40-49 years and 50-59 years). This implies that younger, less experienced teachers have significantly higher levels of agreement for inclusion practices related to 
professional roles and functions than older, more experienced teachers in the present sample.

Level of education also was a noted difference among teachers with the professional roles and functions factor. Teachers with Bachelor's degrees had statistically significantly higher levels of agreement related to professional roles and inclusion of students with autism than teachers with a Master's or Beyond Master's degree. Severity level of autism in students was a also significant variable. Teachers who had students with severe levels of autism had significantly less agreement with inclusion practices related to professional roles and functions than teachers who had students with multiple levels of severity of autism. Teachers with a student with autism in their classes had significantly more agreement with the professional roles and function items than teachers without such students. Finally, teachers who reported having adequate training in autism and those who reported have formal training in autism were also significantly more positive toward inclusion than those teachers who reported that they did not have adequate or formal training in autism.

Statistically significant differences were found with the second factor, beliefs about the efficacy of inclusion (BEI), when evaluated with three teacher characteristics: frequency of contact with a person with autism, $F(4,75)=4.36, p=.002$; adequate autism training, $F(1,1004)=62.70, p=.000$; and formal autism training, $F(1,341)=$ $20.0, p=.000$. Items for Factor $2(\mathrm{BEI})$ were reversed coded to maintain consistency with interpretation across factors. Teacher attitudes regarding the efficacy of inclusion were significantly higher (i.e., more agreement) for teachers who have daily contact with persons who have autism than for teachers who have no contact with persons with 
autism. Teachers who reported having adequate training in autism and those who reported having formal training in autism were significantly more in agreement regarding the efficacy of inclusion than those teachers who reported inadequate and no formal training in autism.

The TATIS Factor 1, which assessed teacher perceptions of students with autism, noted a statistically significant difference for only one teacher characteristic: adequate autism training, $F(1,430)=13.18, p=.000$. Teachers who reported having adequate training in autism had significantly more agreement with inclusion items related to perceptions of students with autism than those teachers who reported not having adequate training in autism.

The total Full Scale score comprises all 14 items on the TATIS. A statistically significant difference was noted for the TATIS total score when examined with three teacher characteristics: severity level of autism, $F(3,586)=5.11, p=.002$; adequate autism training, $F(1,4692)=37.32, p=.000$; and formal autism training, $F(1,2160)=$ $16.65, p=.000$. Teachers who reported having moderate severity level students and students with multiple severity levels had significantly higher levels of agreement with the inclusion statements than those teachers who reported having students with severe levels of autism. Teachers who reported having adequate training in autism and those who reported having formal training in autism were significantly more positive toward inclusive practices for students with autism than teachers without formal or adequate training.

Question 3: Are there differences between regular and special education teachers' attitudes toward inclusion of students with autism? 
An analysis of variance (ANOVA) was conducted to examine the scores for the three factors (POS, BEI and PRF) within the TATIS as well as the TATIS Full Scale score in relation to the variable of regular versus special education teacher. A statistically significant difference was noted with Factor $2(\mathrm{BEI}), F(1,187)=10.79, p=.001$ and Factor $3(\mathrm{PRF}), F(1,181)=10.16, p=.002$ when comparing regular and special education teachers (see Table 6). For both factors, special education teachers had significantly more positive attitudes regarding their beliefs about the efficacy of inclusion and their perceptions of professional roles and functions than regular education teachers. Such results might be expected, given that special education teachers are trained to work with students with special needs and have more experiences with students with special needs.

Data analysis highlighted some noteworthy differences among regular and special educators within the present study (Table $1 \& 2$ ). Special education teachers reported fewer Bachelor's degrees and more educational experience beyond that of a Master's degree when compared with regular education teachers. Special education teachers reported having achieved National Board Certification nearly double that of regular educators. Special education teachers were also more likely to have formal and adequate training in the area of autism. As expected, special education teachers have had more students with autism within their classrooms and have had multiple students with multiple severity levels where regular education teachers have seen fewer students and less severity levels. Even though they did have more training than regular education teachers, $55 \%$ of special education teachers reported no formal training and $57 \%$ reported inadequate training on autism. 
Table 6

Mean Scores for Regular and Special Education Teachers' Attitudes

$\begin{array}{cccc}\text { Factor } 1 & \text { Factor } 2 & \text { Factor } 3 & \text { Total } \\ \text { POS } & \text { BEI } & \text { PRF } & \text { Full Scale }\end{array}$

Teaching Position

$\begin{array}{lllll}\text { Regular Education } & 23.79 & \mathbf{1 8 . 1 1}^{\mathbf{1}} & \mathbf{1 9 . 6 6}^{\mathbf{1}} & 61.56 \\ \text { Special Education } & 23.79 & \mathbf{1 9 . 3 7}^{\mathbf{2}} & \mathbf{2 0 . 9 0}^{\mathbf{2}} & 64.06\end{array}$

Note. Bolded items are statistically significant. Superscripts note items that are significantly different. Items in Factor 2 were reverse coded. POS $=$ Perceptions of students. $\mathrm{BEI}=$ Beliefs about the efficacy of inclusion. $\mathrm{PRF}=$ Professional roles and functions. 


\section{Summary}

This chapter discussed results of the statistical analyses for this research. The present research obtained three separate factors (for the modified TATIS used within this study) that were identical to the factors obtained by Cullen et al. for the original TATIS. Current reliability statistics were acceptable. In summary, the majority of the sample of full-time certified teachers agreed that regular and special education teachers should share the responsibility of educating students with autism and were overall supportive of team teaching and a consultant teacher model as a means for including students with autism. Conversely, most teachers still supported maintaining separate classrooms that exclusively serve students with autism as a means of meeting their educational needs. Almost all regular education teachers and over half of special education teachers reported that they were not adequately trained on autism and denied having formal training on autism.

Most statistically significant differences among teacher characteristics were found when perceptions of professional roles were compared (Factor 3, PRF). When examining teacher beliefs about the efficacy of inclusion (Factor 2, BEI), there was a statistically significant correlation noted with three teacher characteristics: frequency of contact with a person with autism, formal autism training, and adequate autism training. There was also a statistically significant correlation between teacher perceptions of students with autism (Factor 1, POS) and the teacher characteristic of adequate autism training. When the TATIS total score was examined, there were three teacher characteristics with significant correlations: formal autism training, adequate autism training, and severity level of autism. The two characteristics that focused on autism training were statistically 
significant across 2 TATIS factors and the total TATIS score (i.e., Do you have formal training in autism beyond the basics?) and across all 3 TATIS factors and the total TATIS score (i.e., Do you feel adequately trained to teach students who have autism?). 


\section{CHAPTER V}

\section{CONCLUSIONS AND RECOMMENDATIONS}

This research study was conducted to examine teacher attitude toward the inclusion of students with autism within the regular education classroom. The methodology included the use of a selective sample and an e-mailed survey to collect data. The sample included full-time certified teachers currently employed within the Wilderness Trail Education Cooperative (WTEC) in South Central Kentucky for the 2011-2012 school year. This chapter includes a discussion of the findings related to three research questions and how the results relate to the review of the literature.

Recommendations for educational research, school district administration, and policy development are also provided.

\section{Findings}

The sample of certified teachers for this study was described using descriptive statistics. The demographic profile of the present sample are similar to those of certified teachers in the state of Kentucky. Understanding both regular and special education teacher's attitude toward the inclusion of students with autism is important when trying to incorporate educational teaching strategies within the regular education classroom for students with autism. Teachers must be accepting of students with autism as they enter their classrooms and must understand the students' individual needs. Teachers and school administrators must recognize that adequate autism training is critical to successful inclusion for students with autism. 
The research questions were the following:

1. What are the attitudes of public school teachers toward inclusion of students with autism?

2. Are there specific teacher characteristics related to teacher attitude toward inclusion of students with autism?

3. Are there differences between regular and special education teachers' attitudes toward inclusion of students with autism?

Question 1: What are the attitudes of public school teachers toward inclusion of students with autism?

The attitudes of public school teachers toward the inclusion of students with autism was measured using a modified version of the Teacher Attitudes Toward Inclusion Scale (TATIS) developed by Cullen et al. (2010). Overall, teachers were found to be supportive of inclusion for students with autism. Most (83.4\%) were in agreement that the responsibility for educating students with autism lies among regular and special education teachers. Teachers in the present study were in favor of team teaching or a consultant teacher model to support inclusion for students with autism. Over half $(58 \%)$ of the teachers in the present study were willing to modify their classrooms to meet the needs of students with autism. This is consistent with findings from Kasa-Hendrickson and Kluth (2005) who interviewed five elementary teachers that were completely supportive of inclusion and had made multiple adaptations to their classrooms to meet the needs of students with autism.

Although teachers were noted to be overall positive toward the inclusion for students with autism, many (68\%) were supportive of maintaining separate classrooms 
that exclusively serve students with autism. Similarly, nearly half $(49.8 \%)$ reported that it is necessary to remove students with autism from the regular education classroom in order to meet their educational needs. This is consistent with Yianni-Coudurier et al. (2008) who found that the clinical characteristics of autism influenced student placement within the regular education classroom. Teachers were supportive of inclusion yet student time within the regular education settings was noted to decrease as severity of autistic symptoms and aberrant behaviors increased. Findings from Daane et al. (2000) noted that teachers (regular and special education) and administrators disagreed about the effects of students with disabilities on classroom management. Teachers noted increased classroom management problems when students with disabilities were placed into the regular education classroom and administrators did not. As supported by the findings of previous research and the present study, teacher acceptance for inclusion is evident; however, most teachers continue to support separate classrooms as an alternative to meet the educational needs of students with autism. The severity level of the autism appears to play a key role in student time within the regular education setting.

Question 2: Are there specific teacher characteristics related to teacher attitude toward inclusion of students with autism?

Teacher characteristics were obtained using a demographic questionnaire developed by this researcher. Individual teacher demographics were compared with teacher attitude toward inclusion of students with autism as provided by a modified version of the TATIS developed by Cullen et al. (2010). The modified TATIS produces a Full Scale score which includes all survey items and three separate factor scores which are as follows: (a) teacher perceptions of students with autism (POS, 6 items), (b) beliefs 
about the efficacy of inclusion (BEI, 4 items), and (c) perceptions of professional roles and functions (PRF, 4 items). No statistically significant correlations were noted between teacher attitude toward inclusion and the following teacher characteristics: gender, National Board Certification, grade level taught, having a family member with autism, and being personally acquainted with a person with autism.

There was a significant correlation between the teacher characteristic of being adequately trained on autism and all three TATIS factors as well as the TATIS Full Scale score $(p<.01)$. Similarly, the teacher characteristic of having formal autism training was significant for BEI, Factor 2; PRF, Factor 3 and the TATIS Full Scale score $(p<.01)$. Teachers in the present research openly reported a lack of adequate training and formal training on the topic of autism when assessed by the modified TATIS (Cullen et al. 2010). McConkey and Bhlirgri (2003) had similar findings in their study of fifty-six preschool teachers in the United Kingdom. Almost half (46\%) of preschool teachers reported inadequate autism training and over a third (38\%) stated they had no training at all. Cook et al. (1999) found that principals and special education teachers within two southern California counties agreed that regular education teachers do not have the training or skills to meet the needs of students with mild disabilities within the regular classroom yet the majority of principals rated inclusion as the most effective placement for these students. These findings along with the current research suggest a consensus that teachers have lacked sufficient training on disabilities (including autism) for more than a decade yet have continually been asked to teach students who have such disabilities. Understanding this seemingly basic teacher need should provide obvious insight for school administrators for future professional development or program 
development. Specifically, if there is a noted correlation between teacher attitude toward inclusion of students with autism and teacher training on autism, it is imperative that school districts provide adequate and formal training on the topic of autism. Higher education programs can implement such trainings in their teacher preparation programs. Providing teachers with even the basic understanding of autism may improve their effectiveness with and their attitude toward the inclusion students with autism.

The relationship between teacher age along with years of teaching experience and attitude toward inclusion was found to be statistically significant. Younger (20-29 years), less experienced (1-5 years) teachers were more supportive of inclusion than older (40-49 $\& 50-59$ years), more experienced ( 16 + years) teachers when perceptions of professional roles and functions related to inclusion were assessed (PRF, Factor 3). These results are consistent with findings of other studies regarding the personal teacher characteristic of age or teaching experience and attitude toward inclusion of students with disabilities (Sharma \& Chow, 2008; Soodak et al., 1998). This is important for school district administrators to recognize. If teachers are becoming increasingly negative toward inclusion as they age and/or increase their years of experience, safeguards must be in place to support these teachers in order to minimize the negative impact on inclusion evident with age and/or teaching experience. However, this difference might simply be the difference of a younger, more tolerant and adaptive teaching force versus an older, less adaptive group, especially if the latter group have not had adequate training or any training at all. Specific training on autism or disabilities in general could have a positive impact on teacher attitude toward inclusion. Another possibility would be that the teacher may simply need a break from team teaching or collaboration as the years 
increase. Administrators must be cognizant of the impact teachers experience when placed in inclusive settings for multiple years.

The present study noted that teachers with a Bachelor's degree were statistically different than those with a Master's degree or beyond a Master's degree when assessed on professional roles and functions related to inclusion of students with autism (PRF, Factor 3). Teachers with a Bachelor's degree had higher levels of agreement regarding these roles and functions than those teachers with higher degrees. This is inconsistent with Parasuram (2006) who noted teachers with higher levels of education were found to have more positive attitudes toward inclusion of students with disabilities. One might question if this finding was related to the specific population used in that study (India) or the demographics of the participants.

Teacher attitude and frequency of contact with a student who has autism was statistically significant with relation to beliefs about the efficacy of inclusion (BEI, Factor 2). Specifically, teachers who reported daily contact with a person who has autism had more positive attitudes toward the efficacy of inclusion versus those teachers who had no contact with persons who have autism. This finding reinforces the idea that increased teacher knowledge regarding autism (i.e., direct contact) does influence teacher attitude toward inclusion of those students. Having a student with autism in class was statistically significant when compared with teacher perceptions of professional roles and functions (PRF, Factor 3). Teachers who have students with autism in class had more positive ratings than those who did not. Severity levels of autism also significantly impacted teacher ratings. Those teachers with students with severe levels of autism had significantly less agreement with inclusion practices related to teacher professional roles 
and functions (PRF, Factor 3) and significantly less agreement with all rated items (Full Scale) when compared to teachers with students who had moderate or multiple levels of severity. These findings are consistent with Avramidis and Kalyva (2007) who found that teachers rated students with more severe impairments (i.e., autistic spectrum disorders) as much more difficult to accommodate within the regular education setting. Understanding the differences among severity levels of autism is important for school administration. Teachers respond differently to students with varying levels of autism. Teacher training might assist with understanding autism and student needs at each severity level thus providing teachers the training necessary to work with such students within their classrooms.

Question 3: Are there differences between regular and special education teachers' attitudes toward inclusion of students with autism?

Teachers were asked to identify themselves as regular or special educators on a demographic questionnaire developed by this researcher. This specific teacher demographic was compared with teacher attitude toward inclusion of students with autism as provided by a modified version of the TATIS developed by Cullen et al. (2010). A statistically significant difference was noted when comparing regular and special education teachers and their beliefs about the efficacy of inclusion (BEI, Factor 2) and their perceptions of professional roles and functions (PRF, Factor 3). In particular, special educators had significantly more positive attitudes regarding these aspects of inclusive practices when compared with regular educators. Special education teachers report a more positive attitude toward their roles and functions related to inclusion as well as their overall beliefs about the efficacy of inclusion. This is likely based on the fact that 
special education teachers have more contact with students who have autism and indicated that they had more adequate and formal training than regular education teachers.

Many regular education teachers (67.4\%) reported having a student with autism in their class yet the majority reported no formal $(84 \%)$ or adequate $(81.3 \%)$ training on autism. Although they were more likely to have formal and adequate training in the area of autism than their regular education peers, the greater part of special education teachers reported no formal $(55.2 \%)$ or adequate $(57.1 \%)$ training on autism. These alarming findings highlight the momentous need for autism training for all teachers. Teachers are increasingly presented with students who have autism within public education yet training is not provided to address this increase.

Interestingly, there was not a statistically significant difference between regular

and special education teachers with regards to teacher perception of students with autism (POS, Factor 1) or for the overall TATIS Full Scale. This is a refreshing conclusion hinting at the likelihood that regular education teachers do understand the need for students with autism to be educated with their same age peers to the fullest extent possible.

\section{Limitations}

This researcher notes limitations with the present study that could affect the ability to generalize the findings. These include the correlational research design, a relatively new instrument, emailed notification of the survey, and a selective population limited to a specific educational cooperative in South Central Kentucky. 
The correlational research design does not imply causation for teacher attitude toward inclusion of students with autism and thus may limit the usefulness of the present study; however, this design was adequate for the purpose of the current research. Research in the area of teacher attitude toward inclusion of students with autism is limited within the United States. The TATIS is a relatively new survey instrument developed within the United States (Cullen et al., 2010). The original TATIS provided an overall Cronbach alpha estimate at .821. Similarly, this researcher obtained an overall Cronbach alpha estimate at .887 for the modified TATIS. This indicates that as a tool for measuring teacher attitude toward inclusion of students with autism, it has value and should be used for future research in similar settings. The use of an emailed survey notification could have limited results given the fact that some teachers may not use their email accounts or may have limited access to them. The use of a purposive sample in the present study may have limited the homogeneity of the sample. This research may not be representative of a national population of teachers.

\section{Recommendations}

Understanding teacher attitude toward inclusion of students with autism is important to public education. Recommendations are provided for educational policy, educational practice, and future research.

\section{Educational Policy}

Lawmakers must consider the profound effect that inadequate teacher preparation can have on a student with a disability. Inadequately prepared teachers cannot provide effective instruction to students with disabilities if they have little or no formal training with the special education programs or the specific student disabilities found within a 
public school setting. As policymakers examine ways to improve education they must find ways to provide the essential training necessary for teachers within schools as student population within the regular classroom has changed drastically over the past several years. Autism rates have consistently risen and continue to rise. Students with autism can present a varied array of needs within the regular school setting that must be accommodated by regular education teachers. Regular and special education teachers must be provided with adequate training to meet the needs of students with autism as well as those with other disabilities.

As new education policies are developed within the United States, such teacher needs must be considered if we are to provide appropriate educational opportunities to all students with disabilities. Policies at the national level must be provided that can address the needs of teachers and the enormous task they are faced with on a daily basis as they attempt to provide differentiated instruction to such a diverse group of students within the regular education classroom. Policy makers must understand the increase of students with disabilities included within the regular classroom yet the evident lack of training for teachers expected to meet their needs.

\section{Educational Practice}

Understanding specific teacher training needs could be beneficial to administrators in local school districts as well as faculty in higher education who initially prepare teachers for the workforce. Not all teachers are adequately trained on autism before entering the school system nor are they provided training opportunities once they are hired. Most notably, teachers lack adequate formal training on all aspects of special education including specific student disabilities as they enter the teaching profession and 
have minimal professional development opportunities as they proceed to public school settings where they are expected to teach such students.

Local school district policies should reflect current and future research on this topic as local school district administrators plan for professional development. Understanding teacher characteristics that might influence teacher success with inclusion could be momentous as local school districts continue to have a significant increase in students who have autism entering public education. Providing professional development for teachers in the area of autism could provide the teacher with an assortment of teaching strategies that would accommodate many other types of disabilities given the broad spectrum of behaviors found with autism. Local school district administrators must consider the impact of inadequate teacher training as they place students with disabilities within regular education classrooms. Teachers who have had minimal training at the college or university level will be dependent upon the local school district to provide such training.

Many teacher preparation programs at colleges and universities only provide minimal special education coursework for teachers preparing as regular education teachers. Teachers preparing to become regular education teachers are not provided with detailed training on special education programming or the types of student disabilities that may be present within the school setting. This can cause many problems as these teachers enter the workforce and are faced with such students within their regular classrooms and are expected to provide instruction to them. Teacher preparation programs must take note of the increase of inclusion for students with disabilities within schools and prepare teachers before they enter the public school setting. 


\section{Future Research}

Additional research is needed to confirm the identified teacher characteristics related to the positive attitude toward the inclusion of students with autism that were found within the present study. This research could be replicated with certified public school teachers in different parts of Kentucky, different states, or on a national level to further examine the relationship between teacher attitude toward inclusion of students with autism and teacher characteristics currently identified. The present research noted statistically significant correlations between teacher attitude and multiple teacher characteristics. Most notably lack of adequate and formal training on the topic of autism correlated with an increase in negative teacher attitude toward inclusive practices for students with autism.

Equally important was the revelation that as teachers age and increase teaching experience their positive attitude toward inclusion decreased in the present study. If findings were replicated by means of future research, more support for increased teacher training could be made available for school districts. Further research could examine the specific reasoning behind teacher differences in positive attitude for inclusion as they age or increase their teaching experience. The hypothesis suggested by this researcher is that teachers experience teacher burnout given the stress and anxiety associated with the increased demands placed upon them by inclusion.

Another recommendation for future research would be to examine the effect that specific training on autism would have on regular and special education teachers. It would be of interest to determine if training specific to autism is effective and if so, at what level. Specifically, a pre-test/post-test experimental design would provide a wealth 
of information regarding the value of teacher training on autism. Other research designs could also be beneficial such as a qualitative approach that could provide more personal information, which could be valuable information, not provided with a quasiexperimental research design. Listening to what teachers have to say regarding their views of inclusive practices would be invaluable to research on this topic. Additionally, research on a national level could examine the attitudes of regular and special educators across the nation providing a more heterogeneous sample.

Further research could determine if differences would arise between regular and special education teachers if they were equally trained on autism. A quasi-experimental research design could provide this information if equal training were provided to a target group of teachers. This could be done locally as pilot study before a large study is conducted. Given the increase in autism awareness and the momentous parent involvement found with parents of children who have autism, it is important to find ways to improve the educational experience for these students as their presence in the regular education classroom will continue to rise.

As stated previously, the original TATIS is a relatively new instrument. The Cronbach alpha for the original TATIS developed by Cullen et al. (2010) was .821. The alphas for the three factors ranged from .680 to .803 . The Cronbach alpha for the modified TATIS used in this research was .887 and the alphas for the three factors ranged from .833 to .840 . Since the original TATIS had a Cronbach alpha coefficient below .7 and the instrument was modified for the present research, more research is warranted to confirm the reliability and validity of the instrument. This might include future research with a nationally represented population. 


\begin{abstract}
Summary
Understanding teacher attitude toward the inclusion of students with autism is important to public education. As supported by the findings of this research, teachers are overall positive toward the inclusion of students with autism. Negativity appears to grow from the lack of adequate and formal training on autism. Teacher burnout with inclusion of students with autism may also be a factor in some of the negative attitude noted with teachers who were older with more teaching experience. Administrators of public schools and higher education can use this information to improve current and future teachers through education and awareness.
\end{abstract}




\section{REFERENCES}

Alexander, K., \& Alexander, M. D. (2009). American Public School Law. Belmont, CA: Wadsworth, Cengage Learning.

Alghazo, E. M., Dodeen, H., \& Algaryouti, I. A. (2003). Attitudes of pre-service teachers towards persons with disabilities: Predictions for the success of inclusion. College Student Journal, 37, 515-522.

Al-Shammari, Z. (2006). Special education teachers' attitudes toward autistic students in the autism school in the state of Kuwait: A case study. Journal of Instructional Psychology, 33, 170-178.

American Psychological Association. (2000). Diagnostic and statistical manual of mental disorders, $4^{\text {th }}$ ed. Washington, DC: American Psychological Association.

Avramidis, E., \& Kalyva, E. (2007). The influence of teaching experience and professional development on Greek teachers' attitudes towards inclusion. European Journal of Special Needs Education, 22, 367-389.

Bailey, J. (2004). The validation of a scale to measure school principals' attitudes toward the inclusion of students with disabilities in regular schools. Australian Psychologist, 39, 76-87.

Barnett, C., \& Monda-Amaya, L. E. (1998). Principals' knowledge of and attitudes toward inclusion. Remedial and Special Education, 19, 181-192.

Bender, W. N., Vail, C. O., \& Scott, K. (1995). Teachers' attitudes toward increased mainstreaming: Implementing effective instruction for students with learning 
disabilities. Journal of Learning Disabilities, 28, 87-96.

Blacher, J., \& Christensen, L. (2011). Sowing the seeds of the autism field: Leo Kanner (1943). Intellectual and Developmental Disabilities, 49(3), 172-191.

Brackenreed, D., \& Barnett, J. (2006). Teacher stress and inclusion: Perceptions of pre service teachers. Developmental Disabilities Bulletin, 34, 156-176.

Centers for Disease Control. (2012). New data on autism spectrum disorders. Retrieved from http://www.cdc.gov/features/couting autism.

Cook, B. G., \& Cameron, D. L. (2010). Inclusive teachers' concern and rejection toward their students. Remedial and Special Education, 31, 67-76.

Cook, B. G., Semmel, M. I., \& Gerber, M. M. (1999). Attitudes of principals and special education teachers toward the inclusion of students with mild disabilities critical differences of opinion. Remedial \& Special Education, 20, 199-209.

Crockett, J. B., \& Kauffman, J. M. (1998). Taking inclusion back to its roots. Educational Leadership, 56(2), 74-77.

Cullen, J. P., Gregory, J. L., \& Noto, L. A. (2010, February). The teacher attitudes toward inclusion scale (TATIS) technical report. Paper presented at the 33rd Eastern Educational Research Association, Savannah, Georgia.

Daane, C. J., Beirne-Smith, M., \& Latham, D. (2000). Administrators' and teachers' perceptions of the collaborative efforts of inclusion in the elementary grades. Education, 121, 331-339.

DeVellis, R. (2003). Scale Development: Theory and Applications, Second Edition. Thousand Oaks, CA: Sage. 
Eaves, L., \& Ho, H. H. (1997). School placement and academic achievement in children with autistic spectrum disorders. Journal of Developmental and Physical Disabilities, 9, 277-291.

Elliott, S. (2008). The effect of teachers' attitude toward inclusion on the practice and success levels of children with and without disabilities in physical education. International Journal of Special Education, 23, 48-55.

Finke, E. H., McNaughton, D. B., \& Drager, D. R. (2009). All children can and should have the opportunity to learn: General education teachers' perspectives on including children with autism spectrum disorder who require ACC. Augmentative and Alternative Communication, 25, 110-122.

Grider, J. R. (1995). Full inclusion: A practitioner's perspective. Focus on Autistic Behavior, 10(4), 1-11.

Hastings, R. P., \& Oakford, S. (2003). Student teachers' attitudes towards the inclusion of children with special needs. Educational Psychology, 23, 87-94.

Horrocks, J. L., White, G., \& Roberts, L. (2008). Principals' attitudes regarding inclusion of children with autism in Pennsylvania public schools. Journal of Autism \& Developmental Disorders, 38, 1462-1473.

Jindal-Snape, D., Douglas, W., Topping, K. J., Kerr, C., \& Smith, E. F. (2005). Effective education for children with autistic spectrum disorder: Perceptions of parents and professionals. International Journal of Special Education, 20, 77-87.

Jobe, D., \& Rust, J. O. (1996). Teacher attitudes toward inclusion of students with disabilities into regular classrooms. Education, 117, 148-154.

Kanner, L. (1943). Autistic disturbances of affective contact. Nervous Child, 2, 217-250. 
Kasa-Hendrickson, C., \& Kluth, P. (2005). We have to start with inclusion and work it out as we go: Purposeful inclusion for non-verbal students with autism. International Journal of Whole Schooling, 2, 2-14.

Kavale, K. A., \& Forness, S. R. (2000). History, rhetoric, and reality: analysis of the inclusion debate. Remedial and Special Education, 21(5), 279-296.

Kentucky Department of Education. (2011). Kentucky Education Facts. Retrieved from http://www.kde.state.ky.us.

Kosmerl, K. M. (2011). A comparative investigation of general and special education elementary teachers' beliefs about including students with an educational disability of autism in the general education setting. Retrieved from ProQuest. UMI 3486409.

Lanier, N. J., \& Lanier, W. L. (1996). The effects of experience on teachers' attitudes toward incorporating special students into the regular classroom. Education, 117, 234-241.

Larrivee, B., \& Cook, L. (1979). Mainstreaming: A study of the variables affecting teacher attitude. The Journal of Special Education, 13(3), 315-324.

Leatherman, J. M. (2007). “I just see all children as children”: Teachers' perceptions about inclusion. The Qualitative Report, 12, 594-611.

Levins, T., Bornholt, L., \& Lennon, B. (2005). Teachers' experience, attitudes, feelings and behavioural intentions towards children with special educational needs. Social Psychology of Education, 8, 329-343. 
McConkey, R., \& Bhlirgri, S. (2003). Children with autism attending preschool facilities: The experiences and perceptions of staff. Early Childhood Development and Care, $173,445-452$.

McLaughlin, M. J. (2010). Evolving interpretations of educational equity and students with disabilities. Exceptional Children, 76(3), 265-279.

Monahan, R. G., \& Marino, S. B. (1996). Teacher attitudes toward inclusion: Implications for teacher education in schools 2000. Education, 117, 316-321.

Nicpon, M. F., Doobay, A. F., \& Assouline, S. G. (2010). Parent, teacher, and self perceptions of psychosocial functioning in intellectually gifted children and adolescents with autism spectrum disorder. Journal of Autism and Developmental Disorders, 40(8), 1028-38.

Olley, J. G., DeVellis, R. F., DeVellis, B. M., Wall, J. A., \& Long, C. E. (1981). The autism attitude scale for teachers. Exceptional Children, 47(5), 371-372.

Parasuram, K. (2006). Variables that affect teachers' attitudes towards disability and inclusive education in Mumbai, India. Disability \& Society, 21, 231-242.

Park, M., \& Chitiyo, M. (2011). An examination of teacher attitudes towards children with autism. Journal of Research in Special Educational Needs, 11, 70-78.

Park, M., Chitiyo, M., \& Choi, Y. S. (2010). Examining pre-service teachers' attitudes towards children with autism in the USA. Journal of Research in Special Educational Needs, 10(2), 107-114.

Praisner, C. L. (2003). Attitudes of elementary school principals toward the inclusion of students with disabilities. Exceptional Children, 69, 135-145. 
Reber, C. K., Marșhak, L. E., Glor-Scheib, S., \& Noll, M. B. (1995). Attitudes of preservice teachers toward students with disabilities: Do practicum experiences make a difference? Paper presented at the Annual Meeting of the American Educational Research Association, San Francisco, CA.

Richards, G., \& Clough, P. (2004). ITE students' attitudes to inclusion. Research in Education, 72, 77-86.

Robertson, K., Chamberlain, B., \& Kasari, C. (2003). General education teachers' relationships with included students with autism. Journal of Autism and Developmental Disorders, 33, 123-130.

Ruble, L. A., \& Dalrymple, N. J. (2002). Compass: A parent-teacher collaborative model for student with autism. Focus on Autism \& Other Developmental Disabilities, $17(2), 76-84$.

Sanders, J. L. (2009). Qualitative or quantitative differences between asperger's disorder and autism? Historical considerations. Journal of Autism and Developmental Disorders, 39, 1560-1567.

Shade, R. A., \& Stewart, R. (2001). General education and special education preservice teachers' attitudes toward inclusion. Preventing School Failure, 46, 37-42.

Shanker, A. (1995). Full inclusion is neither free nor appropriate. Educational Leadership, 52(4),18-21.

Sharma, U., \& Chow, E. (2008). The attitudes of Hong Kong primary school principals toward integrated education. Asia Pacific Education Review, 9, 380-391. 
Shippen, M. E., Crites, S. A., Houchins, D. E., Ramsey, M. L., \& Simon, M. (2005). Preservice teachers' perceptions of including students with disabilities. Teacher Education and Special Education, 28, 14-22.

Short, C., \& Martin, B. N. (2005). Case study: Attitudes of rural high school students and teachers regarding inclusion. The Rural Educator, 27, 1-10.

Simpson, R. L., Boer-Ott, S. R., \& Smith-Myles, B. (2003). Inclusion of learners with autism spectrum disorders in general education settings. Topics in Language Disorders, 23(2), 116-133.

Snyder, R. F. (1999). Inclusion: A qualitative study of inservice general education teachers' attitudes and concerns. Education, 120, 173-182.

Soodak, L. C., Podell, D. M., \& Lehman, L. R. (1998). Teacher, student, and school attributes as predictors of teachers; responses to inclusion. Journal of Special Education, 31, 480-497.

Van Reusen, A. K., Shoho, A. R., \& Barker, K. S. (2000). High school teacher attitude toward inclusion. The High School Journal, 84, 7-20.

Yell, M. L., Rogers, D., \& Rogers, E. (1998). The legal history of special education: what a long, strange trip it's been! Remedial and Special Education, 19(4), 219-228.

Yianni-Coudurier, C., Darrou, C., Lenoir, P., Verrecchia, B., Assouline, B., Ledesert, B., et al. (2008). What clinical characteristics of children with autism influence their inclusion in regular classrooms? Journal of Intellectual Disability Research, 52, 855-863. 


\section{APPENDIX A}

INSTRUMENT INCLUDING DEMOGRAPHIC QUESTIONNAIRE AND TEACHER ATTITUDE TOWARD INCLUSION SCALE (TATIS) 
Teacher Attitudes Toward Inclusion Scale (TATIS)

Directions: The purpose of this confidential survey is to obtain an accurate and valid appraisal of your perceptions of the inclusion of students with autism in regular classrooms. It also contains questions pertaining to your beliefs about professional roles, attitudes toward collegiality, and perceptions of the efficacy of inclusion (i.e., whether or not you believe that inclusion can succeed). There are no "right" or "wrong" answers to these items, so please respond candidly.

Inclusion: For the purposes of this survey, inclusion is defined as the integration of students with autism into regular classrooms part or all of the school day.

\section{Section 1: Respondent Information}

1. What is your current teaching position?

Regular Education Teacher

$O$ Special Education Teacher

O Resource/Self-Contained

O Collaboration

2. What is your gender?

O Male

O Female

3. What is your degree status?

Bachelor's degree

Master's degree

Beyond Master's degree

4. How many years of teaching experience do you have?

O $1-5$ years

O 6-10 years

O $11-15$ years

16-20 years

O 21 years or more

5. What grade level are you currently teaching?

O Elementary

$O$ Middle

$\mathrm{O}$ High

6. What is your age?

20-29 years

O 30-39 years

40-49 years

O 50-59 years

$060+$ years

7. Do you hold National Board Certification?

O Yes

No

8. Do you have a close family member (e.g. child, sibling or parent) who has autism?

$\mathrm{O}$ Yes

O No
9. Are you personally acquainted with a person who has autism (not a close family member or student)?

$\mathrm{O}$ Yes

O No

10. Describe your frequency of contact on average with a person who has autism (not a student)?

O Daily

O Weekly

O Monthly

$O$ Very Rarely

O Never (Not Applicable)

11. Do you have or have you had a student with autism in your class?

O Yes

O No

12. If you answered "Yes" to question 11, how would you describe the severity level of autism in that student?

O Mild

O Moderate

O Severe

O I've had multiple students at multiple severity levels

13. Do you feel adequately trained to teach students who have autism?

14. Do you have formal training in autism beyond the basics (basics = overview of definition or characteristics of autism)

$\mathrm{O}$ Yes

O No 
Teacher Attitude Toward Inclusion Scale (TATIS)

\section{Section 2: TATIS Survey}

Use the following scale for all items:

1 = Disagree Very Strongly (DVS), $2=$ Strongly Disagree (SD), 3 = Disagree (D), 4 = Neither Agree nor Disagree (NAD), $5=$ Agree (A), $6=$ Strongly Agree (SA), $7=$ Agree Very Strongly (AVS)

1. All students with autism should be educated in regular classrooms with non-handicapped peers to the fullest extent possible.

2. It is seldom necessary to remove students with autism from regular classrooms in order to meet their educational needs.

3. Most or all separate classrooms that exclusively serve students with autism should be eliminated.

4. Most or all regular classrooms can be modified to meet the needs of students with autism.

5. Students with autism can be more effectively educated in regular classrooms as opposed to special education classrooms.

6. Inclusion is a more efficient model for educating students with autism because it reduces transition time (i.e. the time required to move from one setting to another).

7. Students with autism should not be taught in regular classes with non-disabled students because they will require too much of the teacher's time.

8. I have doubts about the effectiveness of including students with autism in regular classrooms because they often lack the academic skills necessary for success.

9. I have doubts about the effectiveness of including students with autism in regular classrooms because they often lack the social skills necessary for success.

10. I find that general education teachers often do not succeed with students with autism, even when they try their best.

11. I would welcome the opportunity to team-teach as a model for meeting the needs of students with autism in regular classrooms.

12. All students benefit from team teaching; that is, the pairing of a general and a special education teacher in the same classroom.

13. The responsibility for educating students with autism in regular classrooms should be shared between general and special education teachers.

14. I would welcome the opportunity to participate in a consultant teacher model (i.e. regular collaborative meetings between special and general education teachers to share ideas, methods and materials) as a means of addressing the needs of students with autism in regular classrooms. 


\section{APPENDIX B}

REVISED TATIS STANDARD SCORE CONVERSION CHARTS 


\begin{tabular}{|c|c|c|c|c|c|}
\hline Raw Score & T-score & $\%$ Rank & Raw Score & T-score & $\%$ Rank \\
\hline$\overline{28 \& \text { under }}$ & 20 & $<1$ & $\overline{63}$ & 51 & 55 \\
\hline 29 & 21 & $<1$ & 64 & 52 & 58 \\
\hline 30 & 22 & $<1$ & 65 & 52 & 58 \\
\hline 31 & 23 & $<1$ & 66 & 53 & 63 \\
\hline 32 & 24 & $<1$ & 67 & 54 & 65 \\
\hline 33 & 25 & 1 & 68 & 55 & 70 \\
\hline 34 & 26 & 1 & 69 & 56 & 73 \\
\hline 35 & 26 & 1 & 70 & 57 & 77 \\
\hline 36 & 27 & 1 & 71 & 58 & 79 \\
\hline 37 & 28 & 1 & 72 & 59 & 82 \\
\hline 38 & 29 & 2 & 73 & 59 & 82 \\
\hline 39 & 30 & 2 & 74 & 60 & 84 \\
\hline 40 & 31 & 3 & 75 & 61 & 87 \\
\hline 41 & 32 & 3 & 76 & 62 & 89 \\
\hline 42 & 33 & 5 & 77 & 63 & 91 \\
\hline 43 & 33 & 5 & 78 & 64 & 92 \\
\hline 44 & 34 & 5 & 79 & 65 & 94 \\
\hline 45 & 35 & 7 & 80 & 65 & 94 \\
\hline 46 & 36 & 8 & 81 & 66 & 95 \\
\hline 47 & 37 & 10 & 82 & 67 & 96 \\
\hline 48 & 38 & 12 & 83 & 68 & 97 \\
\hline 49 & 39 & 14 & 84 & 69 & 97 \\
\hline 50 & 39 & 14 & 85 & 70 & 98 \\
\hline 51 & 40 & 16 & 86 & 71 & 98 \\
\hline 52 & 41 & 19 & 87 & 72 & 99 \\
\hline 53 & 42 & 21 & 88 & 72 & 99 \\
\hline 54 & 43 & 25 & 89 & 73 & 99 \\
\hline 55 & 44 & 27 & 90 & 74 & 99 \\
\hline 56 & 45 & 32 & 91 & 75 & 99 \\
\hline 57 & 46 & 35 & 92 & 76 & $>99$ \\
\hline 58 & 46 & 35 & 93 & 77 & $>99$ \\
\hline 59 & 47 & 39 & 94 & 78 & $>99$ \\
\hline 60 & 48 & 42 & 95 & 78 & $>99$ \\
\hline 61 & 49 & 47 & 96 & 78 & $>99$ \\
\hline 62 & 50 & 50 & $97 \&$ over & 80 & $>99$ \\
\hline
\end{tabular}


Standard Score Conversion Chart for TATIS Factor 1 (POS)

\begin{tabular}{|c|c|c|}
\hline Raw Score & T-score & $\%$ Rank \\
\hline$\overline{6}$ & 19 & $<1$ \\
\hline 7 & 21 & $<1$ \\
\hline 8 & 23 & $<1$ \\
\hline 9 & 24 & $<1$ \\
\hline 10 & 26 & 1 \\
\hline 11 & 28 & 1 \\
\hline 12 & 30 & 2 \\
\hline 13 & 31 & 3 \\
\hline 14 & 33 & 5 \\
\hline 15 & 35 & 7 \\
\hline 16 & 36 & 8 \\
\hline 17 & 38 & 12 \\
\hline 18 & 40 & 16 \\
\hline 19 & 42 & 21 \\
\hline 20 & 43 & 25 \\
\hline 21 & 45 & 32 \\
\hline 22 & 47 & 39 \\
\hline 23 & 49 & 47 \\
\hline 24 & 50 & 50 \\
\hline 25 & 52 & 58 \\
\hline 26 & 54 & 65 \\
\hline 27 & 56 & 73 \\
\hline 28 & 57 & 77 \\
\hline 28 & 59 & 82 \\
\hline 30 & 61 & 87 \\
\hline 31 & 62 & 89 \\
\hline 32 & 64 & 92 \\
\hline 33 & 66 & 95 \\
\hline 34 & 68 & 97 \\
\hline 35 & 69 & 97 \\
\hline 36 & 71 & 98 \\
\hline 37 & 73 & 99 \\
\hline 38 & 75 & 99 \\
\hline 39 & 76 & $>99$ \\
\hline 40 & 78 & $>99$ \\
\hline $41 \&$ over & 80 & $>99$ \\
\hline
\end{tabular}


Standard Score Conversion Chart for TATIS Factor 2 (BEI)

\begin{tabular}{lcc}
\hline & T-score & \% Rank \\
\cline { 2 - 3 } Raw Score & 20 & $<1$ \\
6 under & 23 & $<1$ \\
7 & 25 & 1 \\
8 & 28 & 1 \\
9 & 30 & 2 \\
10 & 32 & 3 \\
11 & 35 & 7 \\
12 & 37 & 10 \\
13 & 39 & 14 \\
14 & 42 & 21 \\
15 & 44 & 27 \\
16 & 47 & 39 \\
17 & 49 & 47 \\
18 & 51 & 55 \\
19 & 54 & 65 \\
20 & 56 & 73 \\
21 & 59 & 82 \\
22 & 61 & 87 \\
23 & 63 & 91 \\
24 & 66 & 95 \\
25 & 68 & 97 \\
26 & 70 & 98 \\
27 & 73 & 99 \\
28 & & \\
\hline
\end{tabular}


Standard Score Conversion Chart for TATIS Factor 3 (PRF)

\begin{tabular}{lcc}
\hline Raw Score & T-score & \% Rank \\
\hline $7 \&$ under & 20 & $<1$ \\
8 & 22 & $<1$ \\
9 & 24 & $<1$ \\
10 & 27 & 1 \\
11 & 29 & 2 \\
12 & 31 & 3 \\
13 & 34 & 5 \\
14 & 36 & 8 \\
15 & 38 & 12 \\
16 & 41 & 19 \\
17 & 43 & 25 \\
18 & 45 & 32 \\
19 & 48 & 42 \\
20 & 50 & 50 \\
21 & 52 & 58 \\
22 & 55 & 70 \\
23 & 57 & 77 \\
24 & 60 & 84 \\
25 & 62 & 89 \\
26 & 64 & 92 \\
27 & 67 & 96 \\
28 & 69 & 97 \\
& & \\
\hline & & \\
\hline
\end{tabular}


APPENDIX C

INFORMED CONSENT 


\section{ASSESSING TEACHER ATTITUDE TOWARD \\ THE INCLUSION OF STUDENTS WITH AUTISM}

April 7, 2011

\section{Dear Certified Teacher;}

You are being invited to participate in a research study by answering the attached survey about teacher attitude toward the inclusion of students with autism into the regular classroom. There are no known risks for your participation in this research study. The information collected may not benefit you directly. The information learned in this study may be helpful to others. The information you provide will be used to help better meet the needs of students with autism and understand teacher attitude toward the inclusion of students with autism. Your completed survey will be stored at the investigator's private office in a locked filing cabinet. The survey will take approximately 10 minutes to complete.

Individuals from the Department of Leadership, Foundations \& Human Resource Education, the Institutional Review Board (IRB), the Human Subjects Protection Program Office (HSPPO), and other regulatory agencies may inspect these records. In all other respects, however, the data will be held in confidence to the extent permitted by law. Should the data be published, your identity will not be disclosed.

Taking part in this study is voluntary. By following the link to the survey you agree to take part in this research study. You do not have to answer any questions that make you uncomfortable. You may choose not to take part at all. If you decide to be in this study you may stop taking part at any time. If you decide not to be in this study or if you stop taking part at any time, you will not lose any benefits for which you may qualify.

If you have any questions, concerns, or complaints about the research study, please contact: Stephanie E. Wilkerson at 270-250-4082.

If you have any questions about your rights as a research subject, you may call the Human Subjects Protection Program Office at (502) 852-5188. You can discuss any questions about your rights as a research subject, in private, with a member of the Institutional Review Board (IRB). You may also call this number if you have other questions about the research, and you cannot reach the research staff, or want to talk to someone else. The IRB is an independent committee made up of people from the University community, staff of the institutions, as well as people from the community not connected with these institutions. The IRB has reviewed this research study.

If you have concerns or complaints about the research or research staff and you do not wish to give your name, you may call 1-877-852-1167. This is a 24 -hour hot line answered by people who do not work at the University of Louisville.

Sincerely,

Stephanie E. Wilkerson

Carl Myers 
APPENDIX D

RECRUITMENT EMAIL 
Dear Certified Teacher,

Hi! My name is Stephanie Wilkerson and I am working on my dissertation at the University of Louisville in an effort to obtain my $\mathrm{PhD}$. I would very much appreciate your time and cooperation with completing a brief survey. Please read the informed consent below that describes the details of the study. If you are willing to participate follow the link to enter the survey.

When you complete the survey, you will have the opportunity to click onto another separate link to provide your name and contact information that will allow you to be entered into a random drawing for an Apple iPad2 that will be given away at the end of data collection!

Thanks for your time!

Stephanie E. Wilkerson 


\section{CURRICULUM VITA}

NAME: $\quad$ Stephanie Elaine Wilkerson

ADDRESS: $\quad$ PO Box 74

Columbia, KY 42728

EDUCATION: $\quad$ 2007-Present: Doctoral student. (ABD) University of Louisville, Educational Leadership and Organizational Development

Ed. S., School Psychology

Western Kentucky University, 2006

M. A., Clinical Psychology

Western Kentucky University, 2004

B. A., Human Services

Lindsey Wilson College, 1994

PROFESSIONAL

CERTIFICATION: Certified as a School Psychologist in the State of Kentucky

CURRENT

EMPLOYMENT: Taylor County School District

School Psychologist/504 Coordinator/RTI Coordinator

PROFESSIONAL

AFFILIATIONS: Kentucky Association for Psychology in the Schools (KAPS)

National Association for School Psychologists (NASP)

American Psychological Association (APA) 